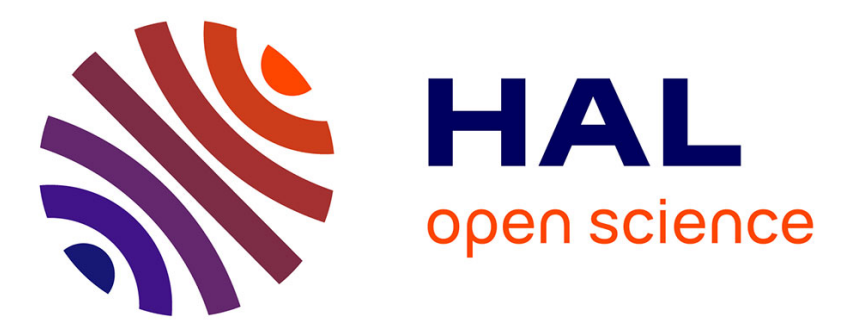

\title{
Interplays between mantle flow and slab pull at subduction zones in $3 \mathrm{D}$ \\ Benjamin Guillaume, F. Funiciello, C. Faccenna
}

\section{To cite this version:}

Benjamin Guillaume, F. Funiciello, C. Faccenna. Interplays between mantle flow and slab pull at subduction zones in 3D. Journal of Geophysical Research: Solid Earth, 2021, 126 (5), pp.e2020JB021574. $10.1029 / 2020 j b 021574$. insu-03220207v2

\section{HAL Id: insu-03220207 \\ https://hal-insu.archives-ouvertes.fr/insu-03220207v2}

Submitted on 21 May 2021

HAL is a multi-disciplinary open access archive for the deposit and dissemination of scientific research documents, whether they are published or not. The documents may come from teaching and research institutions in France or abroad, or from public or private research centers.
L'archive ouverte pluridisciplinaire HAL, est destinée au dépôt et à la diffusion de documents scientifiques de niveau recherche, publiés ou non, émanant des établissements d'enseignement et de recherche français ou étrangers, des laboratoires publics ou privés. 


\section{JGR Solid Earth}

\section{RESEARCH ARTICLE \\ 10.1029/2020JB021574 \\ Interplays Between Mantle Flow and Slab Pull at Subduction Zones in 3D}

Key Points:

- Trench-perpendicular horizontal mantle flow strongly controls trench kinematics and curvature as well as mantle deformation around the slab

- Trench-perpendicular horizontal mantle flow only marginally affects the slab geometry in the vertical plane

- Curvature at subduction margins is independent of slab width and scales with the thickness of the convective layer

Supporting Information:

Supporting Information may be found in the online version of this article.

Correspondence to:

B. Guillaume,

benjamin.guillaume@univ-rennes1.fr

Citation:

Guillaume, B., Funiciello, F., \& Faccenna, C. (2021). Interplays between mantle flow and slab pull at subduction zones in 3D. Journal of Geophysical Research: Solid Earth, 126, e2020JB021574. https://doi. org/10.1029/2020JB021574

Received 18 DEC 2020 Accepted 28 APR 2021

\author{
B. Guillaume ${ }^{1}$ (D) F. Funiciello ${ }^{2}$ (D), and C. Faccenna ${ }^{2,3}$ (D) \\ ${ }^{1}$ University of Rennes, CNRS, Géosciences Rennes, UMR 6118, Rennes, France, ${ }^{2}$ Dipartimento di Scienze, Laboratory \\ of Experimental Tectonics, Università “Roma Tre”, Rome, Italy, ${ }^{3}$ Department of Geological Sciences, Jackson School of \\ Geosciences, The University of Texas at Austin, Austin, TX, USA
}

\begin{abstract}
The understanding of the interactions between subduction-induced mantle flow and background mantle flow (being global or regional) remains incomplete despite its potential impact on subduction dynamics and associated deformation. Here we present the results of three-dimensional laboratory models of subduction zones at the scale of the upper mantle in which we systematically vary the plate's width and trench perpendicular background mantle flow. In particular, we test different mantle flow magnitudes and directions of flow, and evaluate their impact on the slab geometry in the vertical plane, trench shape evolution, and the superficial horizontal mantle deformation. While the chosen viscosity ratio between the convective mantle and the subducting plate in our models $(\sim 100)$ is favorable to the deformation of the slab through mantle displacement, we show that the geometry of the slab in the vertical plane is only marginally affected by the imposed background flow. Instead, the background flow has a larger impact on the horizontal kinematics and deformation of the trench. It reduces along-trench variations of trench kinematics, which in turn decreases trench curvature, and it largely disturbs the pattern of mantle deformation at slab edges, inhibiting the development of toroidal cells. We also show that the thickness of the convective layer (here, the upper mantle) controls the toroidal component of the mantle flow and the length scale of trench curvature for large subduction zones.
\end{abstract}

Plain Language Summary The convective mantle and the lithospheric plates interact on geological time scales to produce plates' displacement and deformation. However, the nature of their interactions is still poorly understood, in particular at subduction zones. Here, we test with new threedimensional laboratory models of subduction, the effect of imposing a trench perpendicular background mantle flow, whose origin could be regional or global, on subduction dynamics. We show that the geometry of the slab in the vertical plane, which would define the Wadati-Benioff zone, is only slightly affected by the magnitude and direction of the imposed flow. These results are at odds with previous twodimensional studies that, by definition, do not allow mantle to flow around slab edges, confirming that the toroidal component of mantle flow is a crucial component of subduction systems that needs to be taken into account while modeling subduction zones. We also show that the imposed background flow controls the velocity at which trenches move horizontally, which in turn impacts the shape of the subduction trench, and the way the mantle deforms around and above the subducting plate.

\section{Introduction}

Subduction zones are places of intense short-term and long-term deformation. However, the mechanisms responsible for such deformation are not yet well constrained. In particular, the long-term nature of the interactions between mantle flow and plates' displacement/deformation is still to be understood. Two end-members exist: (a) the subducting plate through its negative buoyancy drags the convective mantle, mantle flow, in this case being envisioned as "passive” (e.g., Forsyth \& Uyeda, 1975; Hager \& O'Connell, 1979; Lithgow-Bertelloni \& Richards, 1998), (b) plates and slabs are dragged and deformed by an "active" mantle flow. In the latter case, the active mantle flow could be either regional and transient, resulting from the rising of mantle plumes (e.g., Cande \& Stegman, 2011; Obrebski et al., 2010), the sinking of a detached slab (e.g., Coltice et al., 2019; Conrad \& Lithgow-Bertelloni, 2002; Ricard \& Vigny, 1989), the subduction-induced flow from a nearby subduction zone (e.g., Di Leo et al., 2012a; Király et al., 2018), the response to along trench pressure gradients (e.g., Hall et al., 2000; Russo \& Silver, 1994), along-trench slab tearing or slab-window formation (e.g., Guillaume et al., 2010; Sternai et al., 2014), or it could be global 
and may correspond to an "easterly" directed horizontal mantle wind (e.g., Crespi et al., 2007; Cuffaro \& Doglioni, 2007; Ricard et al., 1991). The resulting geometry in the vertical plane of the subducting slab will depend on the velocity of the trench relative to the underlying mantle (Tao \& O'connell, 1992), which is itself sensitive to the interactions between slab pull-induced and externally induced mantle flows. Previous studies also showed that the mantle flow around subduction zones depends to a certain extent on the width of the subduction zone (e.g., Strak \& Schellart, 2016), which can vary on Earth from $\sim 250$ to $\sim 8,000 \mathrm{~km}$ (e.g., Hayes et al., 2018; Heuret \& Lallemand, 2005).

Previous modeling studies have attempted to better understand the effect of interactions between subduction-induced passive flow and active mantle flow by imposing a background mantle flow during subduction. These studies yield contrasted results. 2-D numerical models with imposed background flow show that the slab dip may be largely influenced by an active mantle flow. In particular, a background flow oriented in the same direction as the slab dip may favor flattening of the slab, while in the other direction it is associated with a steeper slab (Ficini et al., 2017; Rodriguez-González et al., 2014). Such variations may go along with different tectonic regimes in the overriding plate, a steeper slab promoting the development of backarc basins (e.g., Ficini et al., 2017; Uyeda \& Kanamori, 1979). These studies also show that the weaker the slab is, the larger the slab dip varies (Rodriguez-González et al., 2014). However, by considering only 2-D subductions, these studies overestimate the role played by the poloidal component of mantle flow, supporting or opposing slab sinking. 2D models lack an important ingredient, that is, the horizontal toroidal flow. The toroidal flow allows the displacement of mantle material around the subduction zone (e.g., Funiciello et al., 2003; Kincaid \& Griffiths, 2003; Piromallo et al., 2006) and has been identified by trench-parallel flow in natural subduction zones (e.g., $\mathrm{Hu}$ et al., 2017). The present-day toroidal/poloidal ratio may be in the range $0.45 \pm 0.1$ (e.g., Becker, 2006; Lithgow-Bertelloni \& Richards, 1998). The integration of poloidal and toroidal components of mantle flow to better reproduce the natural prototype requires three-dimensional modeling. A first study by Boutelier and Cruden (2008) based on 3D analog models has shown that vertical and horizontal mantle flow could impact slab geometry and overriding plate tectonics. However, these models are not truly 3D since the width of the plate is almost identical to that of the box, restricting the toroidal component of mantle flow and limiting the applicability field of the experimental results (Funiciello et al., 2006). In addition, only one direction of the mantle flow is tested and the subduction is kinematically forced by imposing a constant velocity to the subducting plate of $8 \mathrm{~cm} / \mathrm{yr}$, which is identical to that imposed on the mantle. The other existing study in 3D uses numerical models to show that horizontal background flow may have an almost null effect on slab geometry in the vertical plane if directed perpendicular to the trench (Chertova et al., 2018), which is at odds with what was shown in 2D models. It is only when the flow is directed obliquely or parallel to the subduction zone that limited changes of the geometry of the slab, on the scale of $10-50 \mathrm{~km}$, are observed. However, this study also suffers from drawbacks, subduction zones being limited to relatively narrow plates (600-1,400 km width), the subducting plate motion being forced at $1.5 \mathrm{~cm} / \mathrm{yr}$, and the horizontal mantle flow fixed to a single value of $3 \mathrm{~cm} / \mathrm{yr}$. As such, the results may only be applied to a limited range of natural subduction zones.

Here we build upon these previous attempts and go further by using 3-D analog models allowing both poloidal and toroidal components of the mantle flow. We first systematically test the effect of the width of the subducting plate by varying it between the equivalent of $660-4,000 \mathrm{~km}$, covering a large part of present-day subduction zone widths. We then study the interactions between subduction-induced mantle flow and an imposed background horizontal flow. We focus our study on two end-members, considering either that the imposed background mantle flow comes horizontally in a trench-perpendicular direction from the backside (above the slab) or from the foreside (beneath the slab) of the subduction zone. Previous studies proposed that the lithosphere has a net westward drift with respect to the underlying mantle (e.g., Bostrom, 1971; Gripp \& Gordon, 2002). The net rotation of the lithosphere has been estimated at $0.06^{\circ}-0.44^{\circ} / \mathrm{Myr}$ (Becker $\&$ Faccenna, 2009), with a mean angular velocity for the 10 tested models of $0.17^{\circ} / \mathrm{Myr}$, which along the equator would correspond to a velocity of $\sim 1.9 \mathrm{~cm} / \mathrm{yr}$. While we acknowledge that externally imposed mantle flow may not be only global but also regional and therefore, may possibly reach higher values, we explore in this study relative velocity variations between the subducting plate and the convective mantle ranging between 0 and $\sim 2-3 \mathrm{~cm} / \mathrm{yr}$. In particular, we analyze the evolution of the slab geometry in the vertical plane, trench velocity and curvature, and shallow horizontal flow above and around the subducting plate. Finally, we discuss the implications of our results on natural subduction zones. 

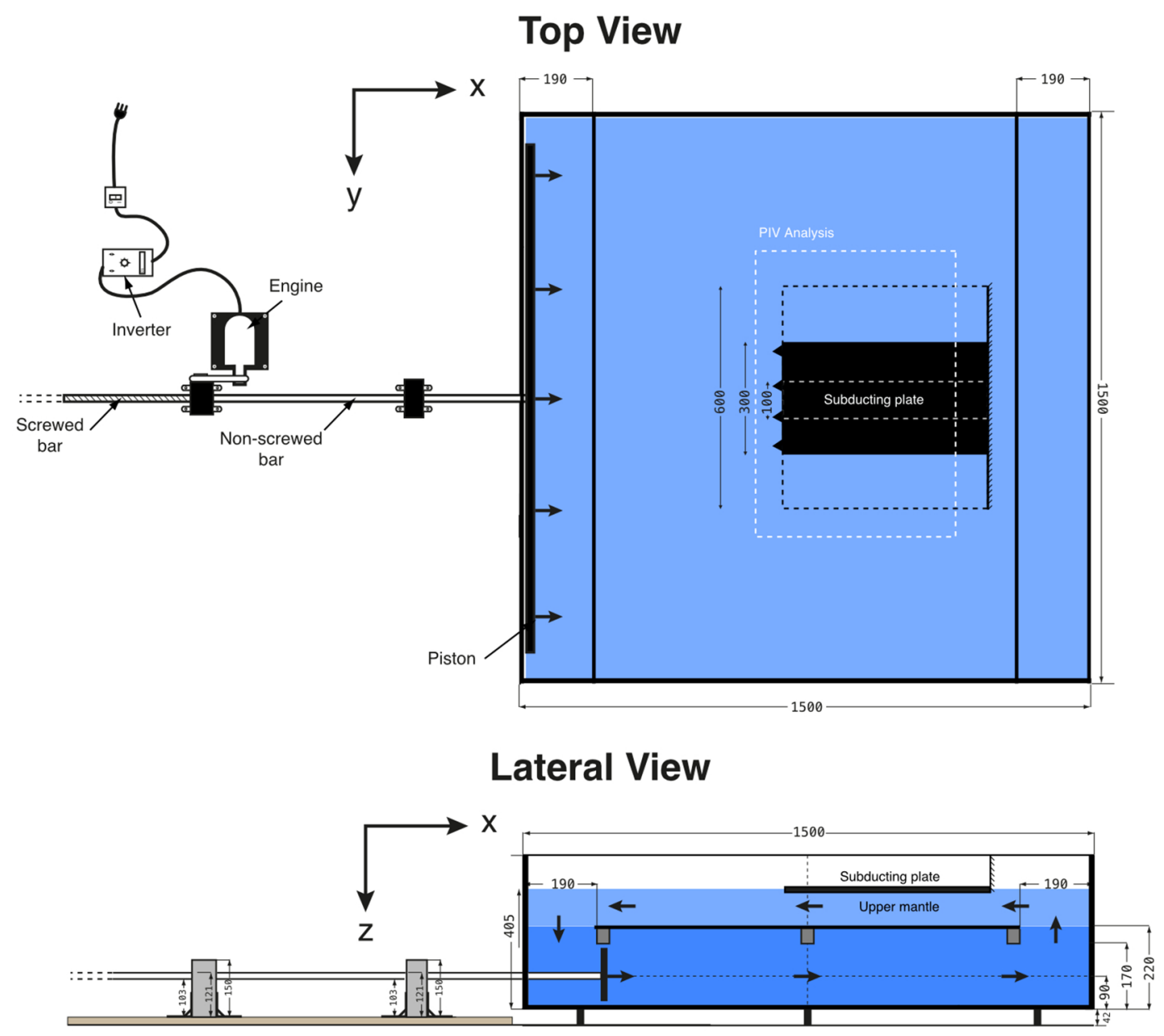

Figure 1. Experimental set-up used in this study. Lengths are given in millimeter. In the lateral view, the light blue corresponds to the upper mantle, the horizontal black line to the impermeable $660 \mathrm{~km}$-discontinuity, and the dark blue to the mantle that is displaced to trigger a background flow in the upper mantle. The different widths of the subducting plate tested in this study and the area where we performed the PIV analysis are indicated in the top view.

\section{Experimental Set-Up}

\subsection{Model}

The experimental apparatus used for this study has been specifically designed to allow background mantle flow control during subduction in the upper mantle. We built a $150 \times 150 \times 40 \mathrm{~cm}^{3}$ Plexiglas tank (Figure 1) in which we fixed an intermediate $1 \mathrm{~cm}$-thick Plexiglas sheet on two walls of the box to reproduce an impermeable upper mantle-lower mantle boundary. This intermediate rigid plate is made $\sim 20 \mathrm{~cm}$ shorter than the box width on the two other sides to allow circulation of mantle material parallel to the subduction direction, the latter being excited by a mobile piston controlled by a motor. Depending on the number of used inverters, we could modulate the piston velocity between 0.15 and $90 \mathrm{~mm} / \mathrm{min}$ and as such encompass a large range of possible horizontal mantle flow. The piston could advance up to $100 \mathrm{~cm}$ below the intermediate plate and operate in both forward and backward directions. The piston is started a few minutes before subduction initiation in order to ensure that the imposed trench-perpendicular background flow is active and stationary when the slab sinks into the underlying mantle. The reference frame of these experiments is the box boundary. It could be considered as the experimental analog of the hot spot reference frame. We took pictures from the top and the side of the experiment at regular intervals for further analysis (Guillaume et al., 2021). 


\subsection{Materials}

The box is filled with glucose syrup (GlucoSweet6284, Tereos Syral), our analog material for sub-lithospheric mantle. The rheological behavior of this material is measured using a Physica MCR 301 (Anton Paar) rheometer, whose accuracy is better than $0.1 \%$, which results in a measurement accuracy less than $5 \%$, as verified by random repeated tests. We tested both the sensibility of the syrup to temperature and applied shear rate (Figure S1). The viscosity of the fluid is independent of shear rate and thus, can be considered as a Newtonian fluid, but it is very sensitive to temperature. Viscosity ranges between $293 \pm 7 \mathrm{~Pa}$ s and $213 \pm 5 \mathrm{~Pa} \mathrm{~s}$ at the minimum and maximum temperatures of $18.8^{\circ} \mathrm{C}$ and $20.7^{\circ} \mathrm{C}$ reached in the lab (Figure S1). Therefore, we precisely control the temperature of the glucose syrup at the beginning of each experiment to scale our models. The temperature is maintained fixed during the evolution of the model. Density of the glucose syrup has been regularly checked and found to be $1,448 \pm 5 \mathrm{~kg} / \mathrm{m} 3$. The dependence of glucose syrup density to temperature is negligible at the temperatures measured in the laboratory.

We model the subducting lithosphere as a viscous sheet floating above the glucose syrup made of transparent silicone putty filled with iron powder. The viscosity of the filled silicone is almost insensitive to temperature and only sensitive to shear rate for values higher than $5 \times 10^{-1} \mathrm{~s}^{-1}$ (Figure S1). The silicone has, therefore, a quasi-Newtonian behavior, with viscosities around $3.25 \pm 0.1 \times 10^{4} \mathrm{~Pa}$ s. At shear rates of $0.01 \mathrm{~s}^{-1}$, and for the range of temperatures recorded during experiments $\left(18.8^{\circ} \mathrm{C}-20.7^{\circ} \mathrm{C}\right)$, the viscosity ratio between lithosphere and mantle is in between 112 and 155, which is within previous estimates of 50-500 (e.g., Billen et al., 2003; Funiciello et al., 2008; Loiselet et al., 2009; Ribe, 2010; Schellart, 2008; Stegman et al., 2010; Wu et al., 2008). The density of the filled silicone is also insensitive to the changes of temperature in the laboratory and equals $1,522 \pm 8 \mathrm{~kg} / \mathrm{m}^{3}$ for models $\mathrm{F} 14-\mathrm{F} 17$ and $1,513 \pm 5 \mathrm{~kg} / \mathrm{m}^{3}$ for models F20-F26. Average negative buoyancy in the lab is, therefore, $74 \pm 13 \mathrm{~kg} / \mathrm{m}^{3}$. Densities and viscosities are assumed to be constant over the thickness of the individual layers and are considered to be averages of the actual values. Length scale ratio between model and nature is $1.52 \times 10^{-7}, 1 \mathrm{~cm}$ in the lab corresponding to $66 \mathrm{~km}$ in nature. The width of the subducting plate is varied between 10 and $60 \mathrm{~cm}$, corresponding to 660-3,960 km in nature, thus covering a large part of the present-day subduction zone widths. Larger plates' width cannot be achieved in the laboratory without deforming the plate during installation prior to subduction initiation, which may have an important impact on subsequent subduction evolution. The thickness of the silicone plate is $1.4 \mathrm{~cm}$, corresponding to $\sim 92 \mathrm{~km}$ in nature. Following the age-thickness relationship:

$$
d=\sqrt{(4 \kappa t)}
$$

we obtain an age for the oceanic lithosphere of $67 \mathrm{Ma}$ for $\kappa=10^{-6} \mathrm{~m}^{2} / \mathrm{s}$. The negative buoyancy of a "normal" $92 \mathrm{~km}$-thick lithosphere is $40 \mathrm{~kg} / \mathrm{m}^{3}$, whereas a fully eclogitized oceanic crust can lead to a negative buoyancy of the subducting lithosphere of $77 \mathrm{~kg} / \mathrm{m}^{3}$ (after Cloos, 1993). Here, the chosen negative buoyancy for the slab $\left(74 \pm 13 \mathrm{~kg} / \mathrm{m}^{3}\right)$ falls close to the higher limit of the proposed buoyancy for a $\sim 70$ Ma-old oceanic lithosphere. However, in the lab, surface tension at the silicone-syrup-air interface, which prevents the plate to sink into the mantle, inhibits subduction to some extent, a process that does not exist in these proportions on Earth. A plate with a density higher than that normally required in Nature is therefore necessary to maintain buoyancy-driven subduction.

Scaling for time between the models and nature is achieved as follows:

$$
\frac{t_{n}}{t_{m}}=\frac{(\Delta \rho g h)_{m}}{(\Delta \rho g h)_{n}} \frac{\eta_{n}}{\eta_{m}}
$$

where subscripts $m$ and $n$ stand for model and nature, respectively, $\Delta \rho$ is the density contrast between the subducting plate and surrounding mantle, $h$ is the slab thickness, and $\eta$ the mantle viscosity. Effective viscosity of the sub-lithospheric upper mantle in Nature is not well constrained. It may vary between $10^{19}$ and $10^{21} \mathrm{~Pa}$ s depending on the depth (Mitrovica \& Forte, 2004). On average, it may be around $5 \times 10^{20} \mathrm{~Pa} \mathrm{~s}$, meaning that $1 \mathrm{Myr}$ in nature corresponds to 139 and $88 \mathrm{~s}$ in the laboratory for the models with the lowest and highest syrup temperatures, respectively (Table 1). Scaling for velocity is obtained as follows: 
Table 1

Main Characteristics and Scaling of the Set of Analog Models

\begin{tabular}{lcccc}
\hline Model & $v_{\text {flow }}(\mathrm{cm} / \mathrm{yr})$ & Width $W(\mathrm{~km})$ & 1 Myr $(\mathrm{s})$ & $5 \mathrm{~cm} / \mathrm{yr}(\mathrm{mm} / \mathrm{min})$ \\
\hline F14 & 0 & 2,000 & 100 & 4.5 \\
F15 & 0 & 660 & 100 & 4.5 \\
F16 & 0 & 4,000 & 97 & 4.7 \\
F17 & 0.9 & 2,000 & 88 & 5.2 \\
F20 & 2 & 2,000 & 105 & 4.3 \\
F24 & -1.2 & 2,000 & 130 & 3.5 \\
F26 & -2.7 & 2,000 & 139 & 3.3 \\
\hline
\end{tabular}

$$
\frac{v_{n}}{v_{m}}=\frac{L_{n} t_{m}}{L_{m} t_{n}}
$$

with $L$ the plate thickness, for instance. Five centimeters per year in Nature corresponds to $\sim 3.3 \mathrm{~mm} / \mathrm{min}$ and $\sim 5.2 \mathrm{~mm} / \mathrm{min}$ for the models with the lowest and highest syrup temperatures, respectively.

In the following, we directly express the quantities with their corresponding scaled values for homogeneities between models in which the absolute viscosity of the mantle is slightly temperature-dependent and for a better relevance to the natural prototype.

Our models are also built up under unavoidable limitations which are listed below:

1. Thermal effects are neglected during the experimental subduction process. Temperature is translated into density contrast, staying constant throughout the experiments. The subducted lithosphere is thus, thought to be in a quasi-adiabatic condition where conduction is limited.

2. The isothermal system also implies the impossibility to simulate the important role of phase changes in slab dynamics (e.g., King, 1998). In particular, we consider the upper-lower mantle transition as an impermeable barrier, simulating a sharp infinite increase in viscosity. This approximation is in agreement with results showing how the effect of a viscosity increase with depth overcomes the one exerted by phase transformations (e.g., Lithgow-Bertelloni \& Richards, 1998).

3. The overriding plate is not modeled allowing to isolate the sole effect of mantle flow on the subducting plate. As we were also interested in mapping horizontal mantle flow around and above the slab, the addition of an overriding plate would have prevented any quantitative analysis. Our choice implies that the effective viscosity of the subduction megathrust is assumed to be as weak as the upper mantle. This choice, justified by the low shear friction characterizing the subduction megathrust (e.g., Capitanio et al., 2010; Duarte et al., 2015; Sobolev \& Brown, 2019; Zhong \& Gurnis, 1994) is able to influence the rate of the subduction process but not the overall behavior (King \& Hager, 1990).

4. The upper-lower mantle discontinuity is simulated by an impermeable barrier. This choice is justified by the lack of a direct penetration of the slab through the transition zone, if the viscosity increase in the lower mantle is at least of an order of magnitude and if the time-scale of the analyzed process is limited (order of few tens of million years) (e.g., Christensen, 1996; Davies, 1995; Funiciello et al., 2003; Guillou-Frottier et al., 1995). The former condition mirrors the Earth system where the increase in viscosity across this discontinuity is supposed to be of 10-100 (e.g., Forte \& Mitrovica, 1996; Hager, 1984; Hager \& Richards, 1989; King \& Hager, 1994). The latter condition is guaranteed by the fact that our models reproduce only the short-term evolution of the subduction process ( $<75 \mathrm{Myr}$ ). The lack of a lower mantle implies that the mantle flow is restricted to the upper mantle.

5. The mantle rheology is simplified using a Newtonian fluid, despite laboratory data indicating that upper mantle materials should obey a deformation creep power law (Brace \& Kohlstedt, 1980). As a Newtonian material, the experimental mantle has a stronger response to deformations than a power-law fluid (Ranalli, 1995) and consequently, the experimental velocities have to be considered as a lower bound.

\section{Forces at Work}

Our simplified subduction system is designed to impose a straightforward force balance that approximately reproduces that of plate tectonics (Figure 2). The only driving force common to all models is the slab negative buoyancy force $\left(F_{s p}\right)$ :

$$
F_{s p}=\left(\rho_{l}-\rho_{m}\right) g W l h
$$

where $\rho_{l}$ and $\rho_{m}$ are the density of subducting lithosphere and sub-lithospheric mantle, respectively, $g$ is the gravitational acceleration, $W, l$, and $h$ are the width, length, and thickness of the subducted lithosphere. 


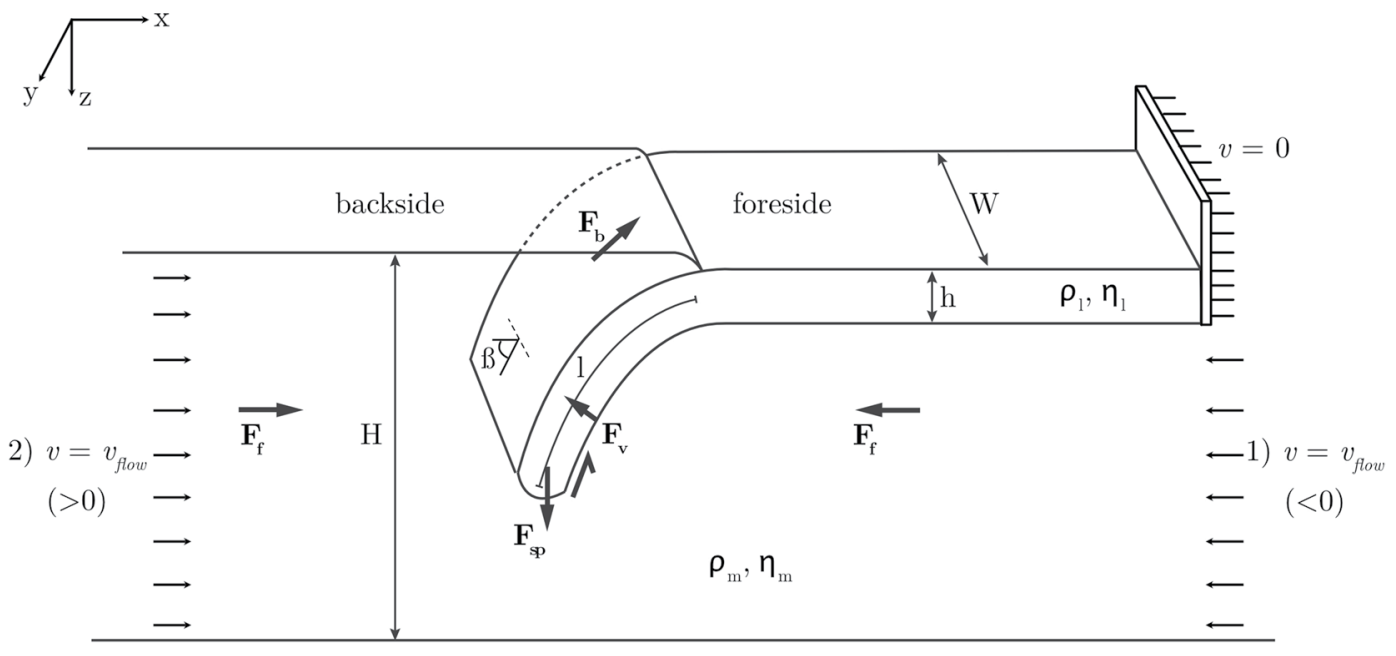

Figure 2. Forces at work in the subduction system. $W$ : plate width; $h$ : plate thickness; $H$ : plate + upper mantle thickness; $l$ : length of subducted lithosphere; $\beta$ : dip of the slab; $\rho_{l}$ : plate density; $\rho_{m}$ : mantle density; $\eta_{l}$ : plate viscosity; $\eta_{m}$ : mantle viscosity. Main forces in our system are the slab pull force $\left(F_{s p}\right)$, the plate bending force $\left(F_{b}\right)$, the resisting viscous forces $\left(F_{v}\right)$, and the flow-induced viscous force $\left(F_{f}\right)$. We fix a zero-velocity boundary condition at the trailing edge of the subducting plate, implying that the ridge push force is either null or a resisting force.

Ridge push force $\left(F_{r p}\right)$, which is around one order of magnitude lower than the slab pull force (Turcotte \& Schubert, 1982), is not implemented in our system. Instead, we chose to fix the velocity boundary at the trailing edge of the subducting lithosphere to a zero velocity to control the relative velocity difference between the sub-lithospheric mantle and the plate in the models with imposed background flow. This no motion boundary condition is independent of the forces at play, which implies that $F_{r p}$ constantly adjusts to balance the trenchward force that applies to the plate. In that mode, it implies that, as opposed to the situation on Earth, $F_{r p}$ is a resisting force.

Additional resistive forces in the system include slab bending $\left(F_{b}\right)$ that can be approached by the following equation (Buffett, 2006):

$$
F_{b}=\frac{2}{3}\left(\frac{h}{R}\right)^{3} \eta_{l} v
$$

where $R$ is the minimum radius of curvature of the bending slab, $\eta_{l}$ the effective viscosity of the slab, and $v$ the subduction velocity. Last, viscous shear forces $\left(F_{v}\right)$ produced by both the sinking and the rollback of the slab into the mantle have no proper analytical solution besides scaling $F_{v}$ with $\eta_{m} v$ and $\eta_{m} v_{r b}$ (where $v_{r b}$ is the rate at which the slab rolls back), respectively.

In the experiments with imposed background flow, viscous forces produced by mantle displacement on subducting lithosphere $\left(F_{f}\right)$ can act as a driving or resisting force depending on the direction of the mantle flow with respect to the vergence of the subduction. In the following, we refer to the side of the unsubducted portions of the plate as the foreside and conversely, the backside is the region above the sunken slab (Figure 2). For mantle flow coming from the backside, viscous forces associated to mantle flow exert an overpressure on the subducting panel that favors slab rollback and, given the no velocity boundary condition for the subducting plate, promotes subduction. Conversely, mantle flow coming from the foreside dynamically supports the slab and prevents it from rolling back, constituting a resisting force.

\section{Results}

\subsection{Reference Model (Model F14): Calibrating Subduction-Induced Mantle Flow}

This first model has been run to calibrate both trench kinematics and mantle deformation in the absence of external velocity boundary conditions. We measure instantaneous trench velocity along cross-sections 

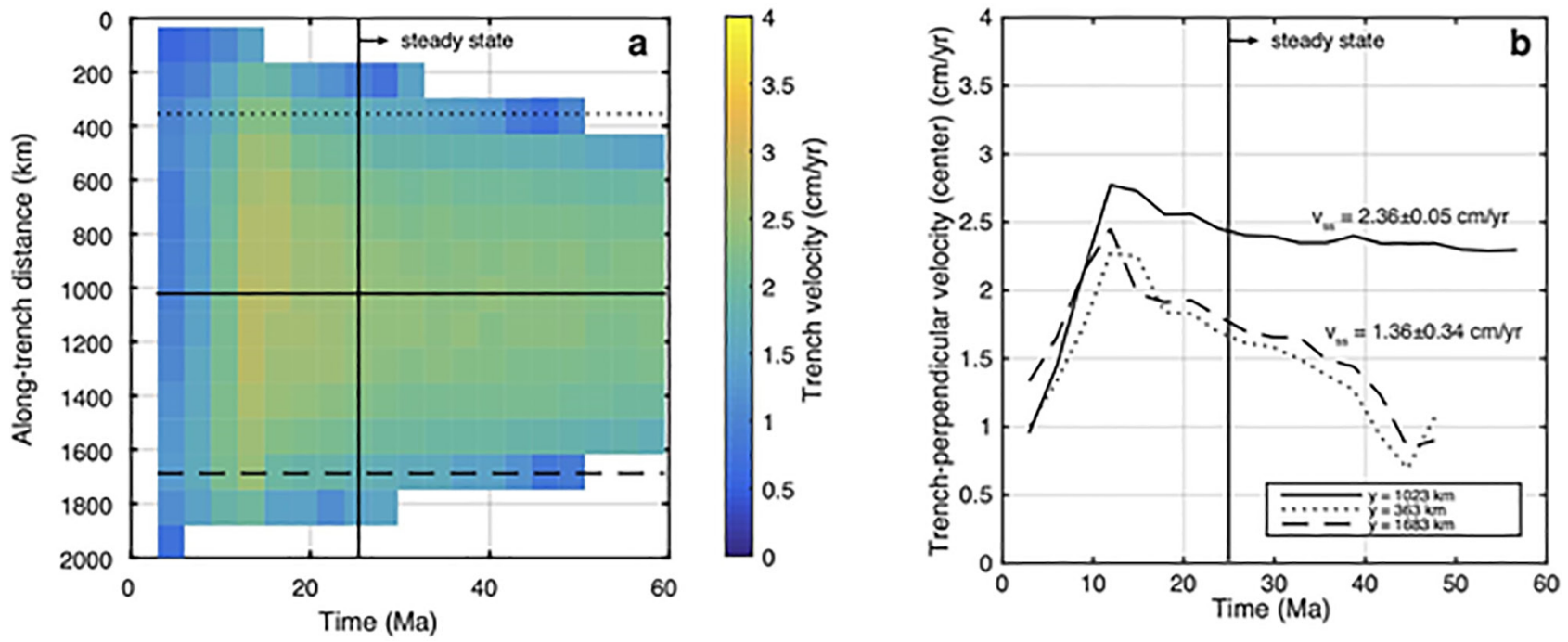

Figure 3. Trench kinematics for the reference model (F14). (a) Evolution of the trench velocity (color map) as a function of time and along-trench distance. Trench motion toward the foreside of the subduction zone (trench retreat) is considered positive. (b) Time evolution of trench velocity in the center (solid line) and at the edges of the subduction zone (dotted and dashed lines). Precise locations of the profiles are indicated on Figure 3a.

separated from each other by $2 \mathrm{~cm}$ (132 km in nature) between pictures taken every 5 min (3 Myr in nature). The time evolution of trench kinematics follows a classic 3 stages evolution, as described in previous studies (e.g., Faccenna et al., 2001; Funiciello et al., 2003; Guillaume et al., 2010): (a) acceleration of the slab during its descent into the upper mantle, (b) transient behavior due to the interaction with the bottom of the tank, and (c) steady state subduction with the slab folding on the $660 \mathrm{~km}$ discontinuity. During the latter phase, the slab exhibits the usual rollback subduction mode, solely driven by the negative buoyancy of the slab and resisted by both the slab bending and the viscous flow in the glucose syrup (Figure 3a). Trench rollback velocity stabilizes at around $2.4 \mathrm{~cm} / \mathrm{yr}$ in the center of the plate, whereas velocity decreases on its edges as the slab deforms (Figure $3 \mathrm{~b}$ ). The center to edge trench velocity ratio during steady-state is around 1.7. The trench retreats while the slab sweeps back into the glucose syrup, which in turn is displaced from the foreside to the backside of the model, thanks to a combination of poloidal and toroidal flows (e.g., Crameri \& Tackley, 2014; Funiciello et al., 2006; Husson et al., 2012; Jadamec \& Billen, 2010; Király et al., 2017; Piromallo et al., 2006; Stegman et al., 2006).

Because of technical limitations, we only image and quantify the toroidal component of mantle flow at the surface of our experiments by using the PIVlab tool for MATLAB (Thielicke, 2014; Thielicke \& Stamhuis, 2014) (Figure 4). We used the FFT Window deformation method with three passes with $256 \times 256 \mathrm{px}^{2}$, $128 \times 128 \mathrm{px}^{2}, 64 \times 64 \mathrm{px}^{2}$ interrogation areas, respectively, and a 50\% step for each pass. We thus, obtain a velocity field with a space resolution of $32 \times 32 \mathrm{px}^{2}(50 \times 50 \mathrm{~km}$ in nature $)$ that we filter with a $3 \times 32$-D median filter. Mantle flow cannot be computed below the subducting plate because the plate is opaque. Because of the resolution of the technique, computation of mantle flow along the edges of the horizontal portion of the subducting plate is also influenced by the deformation of the plate. It leads in the first mm from the plate to mantle-flow streamlines that are parallel to the edge of the plate, which must be considered as an artifact. Toroidal flow is persistent during the entire experiment and velocities up to around $4 \mathrm{~cm} / \mathrm{yr}$ are observed above the slab (Figure 4). While not imaged here, previous studies have shown that the poloidal flow maintains during the different stages of subduction (e.g., Faccenna et al., 2010; Funiciello et al., 2004) (Figure 4).

Strain rate tensor is derived from the velocity field following the procedure by Cardozo and Allmendinger (2009) using the "Grid-Nearest Neighbor" algorithm taking eight nearest neighbors (Figure 5). Horizontal strain at the surface of the mantle driven by slab roll-back mainly consists of trench perpendicular extension and trench-parallel shortening in front of the subduction zone at maximum rates of $\sim 1-1.5 \times 10^{-15} \mathrm{~s}^{-1}$. The width of the zone of trench-perpendicular extension above the slab narrows as the slab rolls back and the trench concavity increases (Figure $5 \mathrm{c}$ ). At the edges of the subduction zone, the direction of maximum 
a) 13.5 Myr

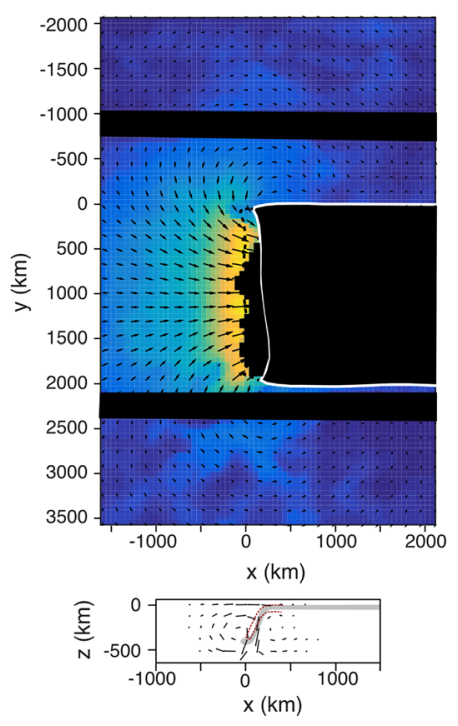

b) $31.5 \mathrm{Myr}$

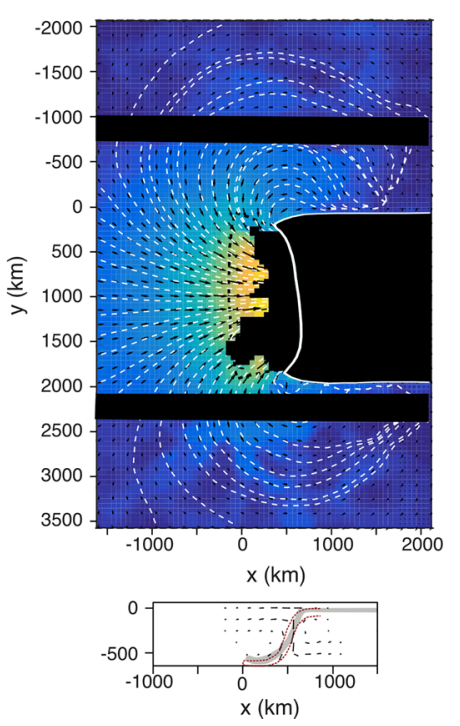

c) $50 \mathrm{Myr}$

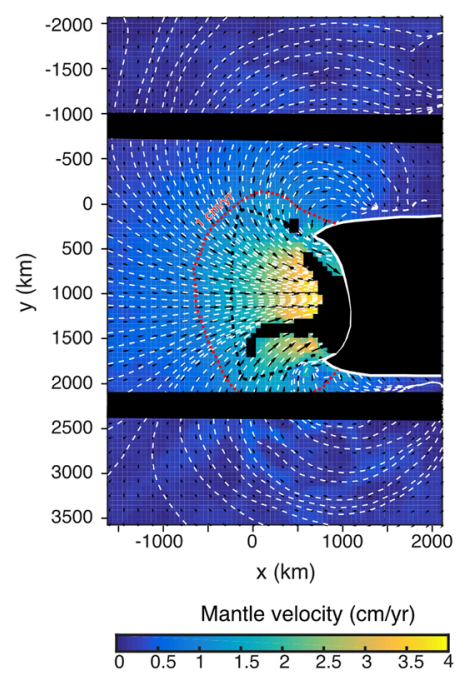

Figure 4. Instantaneous horizontal mantle flow for the reference model after (a) $13.5 \mathrm{Myr}$, (b) $31.5 \mathrm{Myr}$, and (c) $50 \mathrm{Myr}$ ( $1,000 \mathrm{~km}$ ) of subduction. The top view does not encompass the entire modeled domain, whose surface represents $10,000 \times 10,000 \mathrm{~km}^{2}$. The horizontal part of the subducting plate is outlined in white. Black areas indicate zones with poorly resolved image correlation, generally caused by overexposure. Black dotted lines indicate the projection at the surface of slab extension at depth. White dashed lines correspond to streamlines. In Figure 4c, the red dotted line represents a mantle flow velocity of $1 \mathrm{~cm} / \mathrm{yr}$. The bottom figures represent the mantle flow pattern expected in the vertical plane for the subduction initiation stage (left) and steady-state stage (center), as extracted from Faccenna et al. (2010) (black arrows and gray slab). The red dotted lines outline the geometry of the slab in our models at 13.5 and 31.5 Myr.

stretching gradually varies from trench-perpendicular above the slab to trench-parallel away from the slab, the orientation being maintained during the entire subduction (Figure 5).

\subsection{Models With Variable Subducting Plate Width (Models F15 and F16)}

We performed two additional models to understand the role of plate width in controlling trench kinematics and shape (Figure 6), as well as subduction-induced horizontal mantle flow (Figure 7). The models are identical to the reference model but include plates of $660-\mathrm{km}$ width (model F15) and 4,000-km width (model F16) instead of 2,000-km width.

\subsubsection{Kinematics and Trench Curvature}

The $660-\mathrm{km}$ wide plate model does not show first-order differences with the reference model. The subduction is characterized by the same three stages described above. The trench rollback rate at steady-state is only slightly larger on average for the narrower plate (Figure 6d). The trench exhibits a concave shape toward the backside, but unlike the reference model, the center to edge velocity ratio is low, and falls close to 1. The trench curvature is defined as the ratio between the maximum difference in the $x$-direction of trench position $(h)$ over the maximum difference in the $y$-direction of trench position $(W)$. After the subduction reaches a steady-state regime, the curvature of the trench linearly increases for the 2,000-km wide slab up to $\sim 0.3$ after $60 \mathrm{Myr}$ while for the $660-\mathrm{km}$ wide slab the curvature does not increase linearly (Figure 6e).

Larger differences arise when increasing plate width from 2,000 to 4,000 km. The first phase of subduction is marked by a large difference in trench velocity along the subduction zone. In the center of the subduction zone and at the edges, the trench velocity remains quite low $(<1 \mathrm{~cm} / \mathrm{yr})$ during a period equivalent to $10-15 \mathrm{Myr}$, while velocities up to $2.5 \mathrm{~cm} / \mathrm{yr}$ are recorded at the same time for areas located in between (Figure 6c). This variability results in a much complex trench shape, with two lobes concave toward the backside at the edges of the subduction zone and a central area convex toward the backside. This shape develops during the initial stage of subduction and is further amplified during the rest of the subduction process, the width of the subduction zone progressively reducing as the slab rolls back. It is, for instance, 2,800 km after $\sim 75 \mathrm{Myr}$ of subduction. During the final steady-state subduction, the trench retreat velocity 
a) $13.5 \mathrm{Myr}$
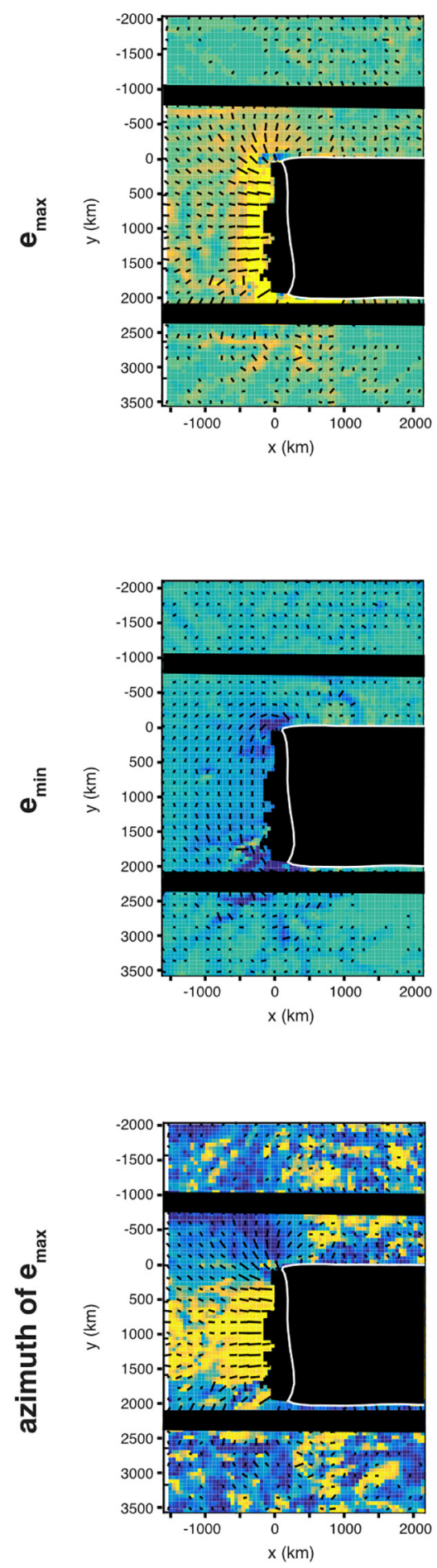

b) $31.5 \mathrm{Myr}$
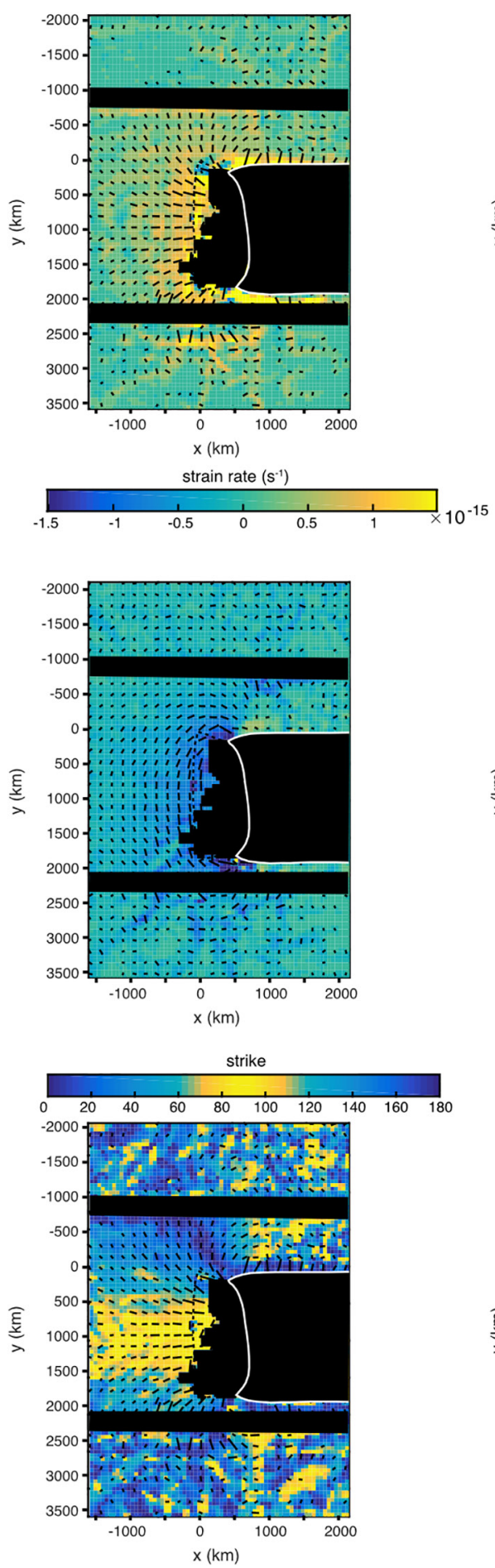

c) $50 \mathrm{Myr}$

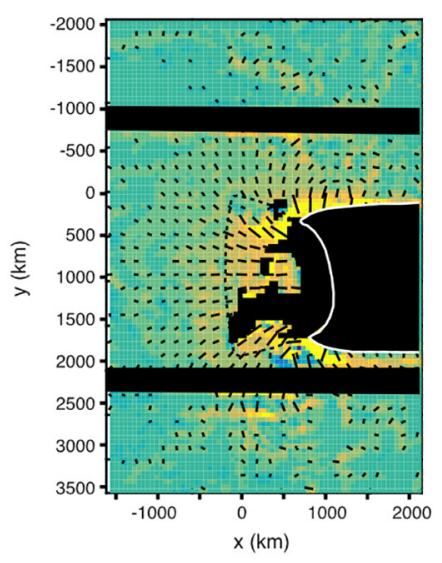

$10^{-15}$
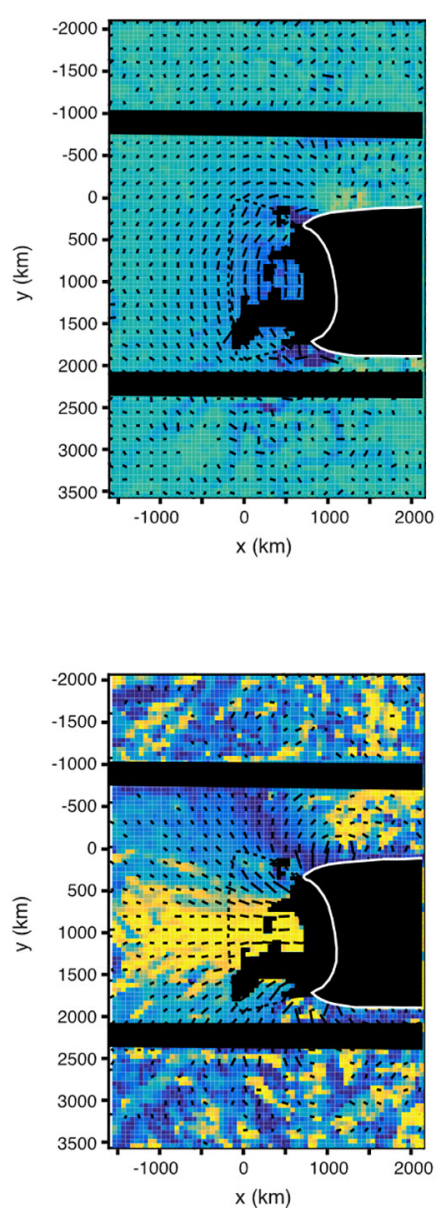

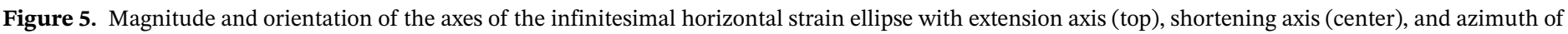
the extension axis (bottom) for the reference model after (a) $13.5 \mathrm{Myr}$, (b) $31.5 \mathrm{Myr}$, and (c) $50 \mathrm{Myr}$. 
a) $\mathrm{W}=660 \mathrm{~km}(\mathrm{~F} 15)$

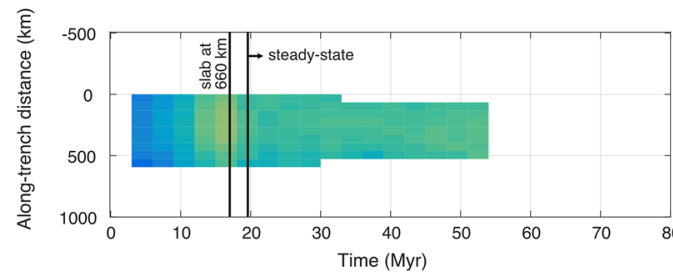

b) $\mathrm{W}=2000 \mathrm{~km}(\mathrm{~F} 14)$
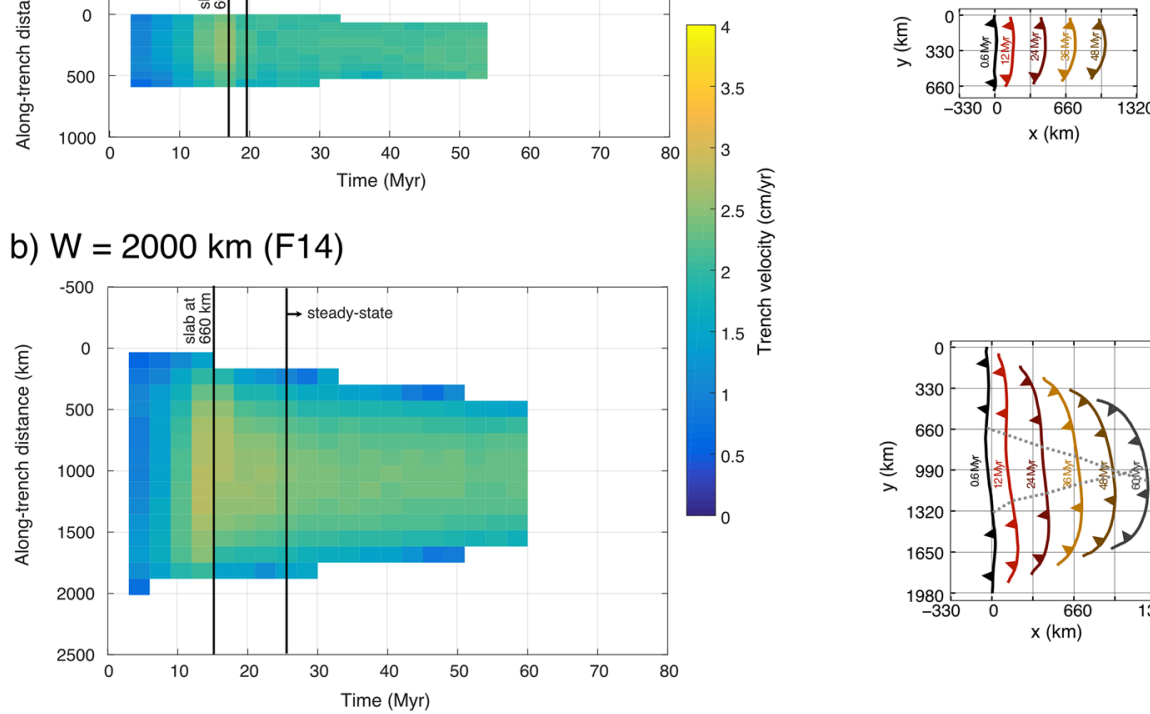

c) $W=4000 \mathrm{~km}(\mathrm{~F} 16)$
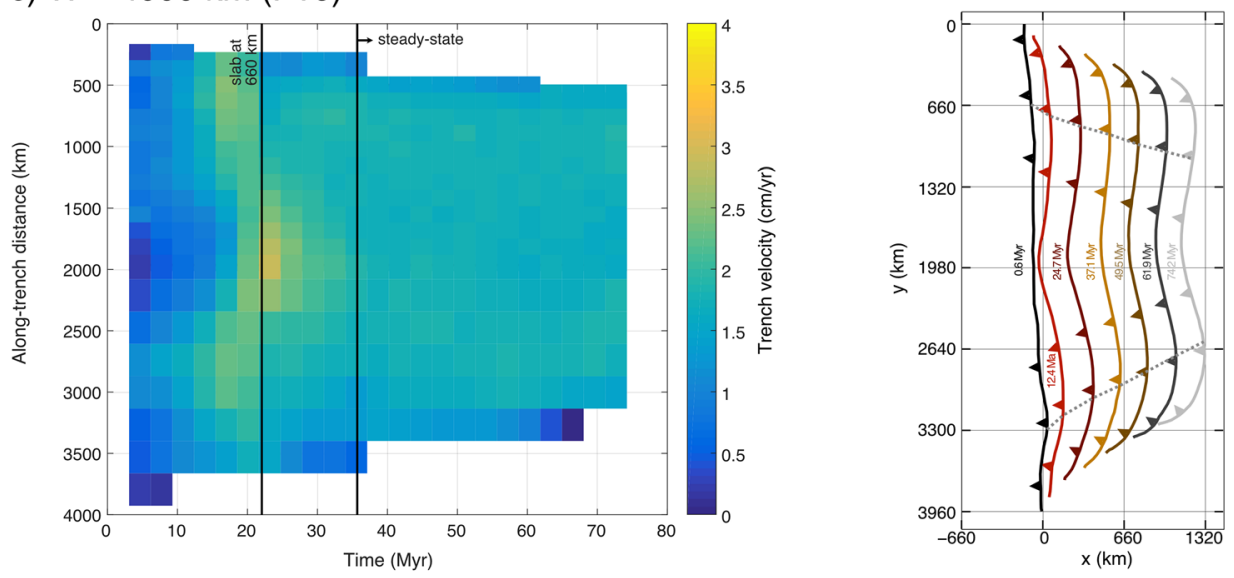

d) trench average velocity

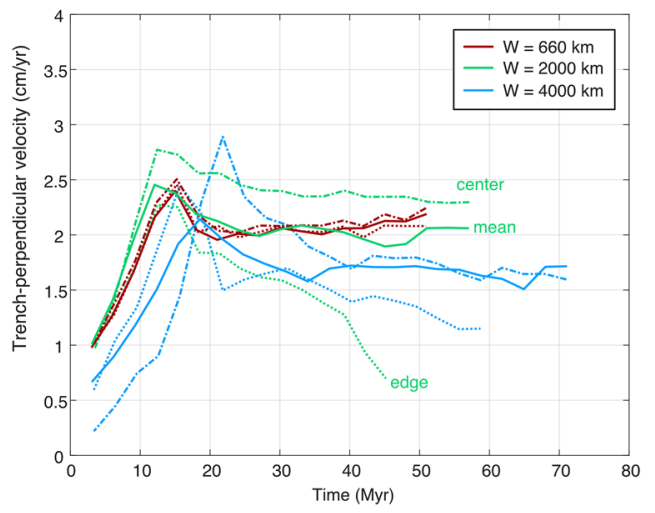

e) trench curvature

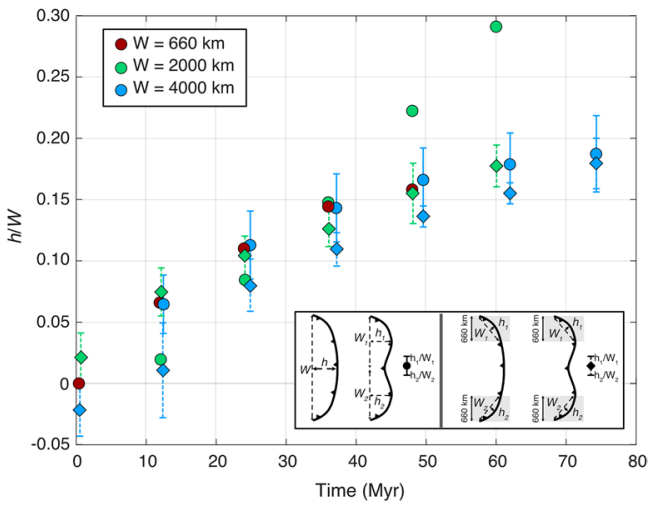



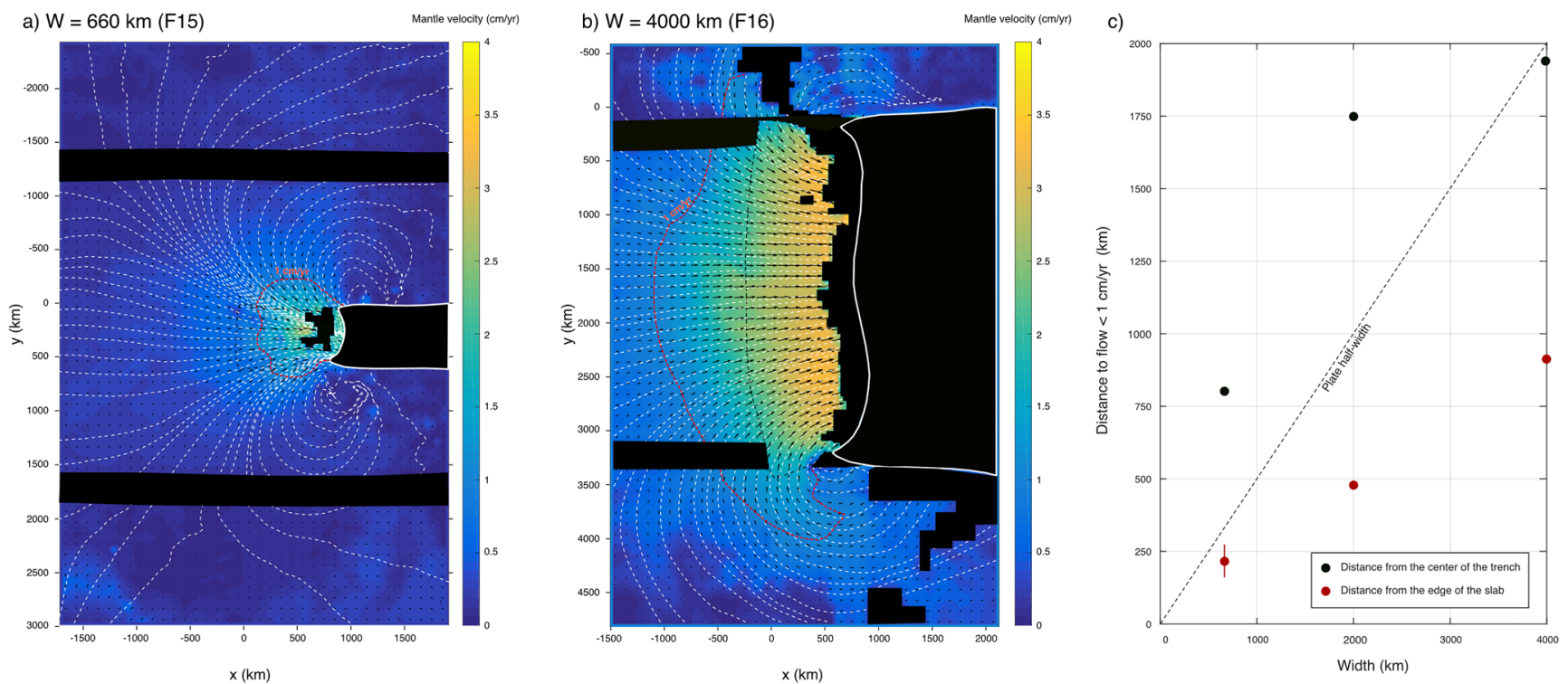

Figure 7. Instantaneous horizontal mantle flow for (a) model F15 ( $W=660 \mathrm{~km})$ and (b) model F16 ( $W=4,000 \mathrm{~km})$ after $50 \mathrm{Myr}$ of subduction. The top views do not encompass the entire modeled domain. Black areas indicate zones with poorly resolved image correlation, generally caused by overexposure. Black dotted lines indicate the projection at the surface of slab extension at depth. The white dashed lines correspond to streamlines and the red dotted lines to mantle flow velocity of $1 \mathrm{~cm} / \mathrm{yr}$. (c) Diagram showing the distance from the center of the trench (black dots) and from the edges of the trench (red dots) to areas where the magnitude of the horizontal mantle flow falls below $1 \mathrm{~cm} / \mathrm{yr}$. The black dotted line indicates the plate half-width.

is around $0.4 \mathrm{~cm} / \mathrm{yr}$ lower than the reference model and the variability between the center and the edge is much reduced (Figure $6 \mathrm{~d}$ ). Unlike the reference model, the average curvature for the two lobes does not increase linearly, it tends toward a plateau close to values of 0.2 .

\subsubsection{Mantle Flow}

Horizontal mantle flow induced by plate subduction is computed after $50 \mathrm{Myr}$, once steady-state subduction is established (Figure 7). Like in the reference model, slab roll back is accommodated by two symmetrical toroidal cells with flow coming from the foreside to the backside area. While the overall pattern of the horizontal mantle flow appears similar irrespective of the plate width, some differences arise. For the narrow plate, the flow is less vigorous. The maximum horizontal velocity is lower than that in the reference model, and the area where significant $(>1 \mathrm{~cm} / \mathrm{yr}$ ) mantle displacement occurs is much reduced. The opposite is observed for the large plate model with fast horizontal motion above the slab $(>3 \mathrm{~cm} / \mathrm{yr})$ and a large area of mantle stirred at velocities higher than $1 \mathrm{~cm} / \mathrm{yr}$. The distance in the $y$-direction between the slab edge and areas with velocities lower than $1 \mathrm{~cm} / \mathrm{yr}$ increases linearly with plate width while the distance in the $x$-direction between the trench and areas with velocities lower than $1 \mathrm{~cm} / \mathrm{yr}$ appears to saturate at around $2,000 \mathrm{~km}$, even for the 4,000 km-wide plate (Figure 7c).

\subsection{Models With Mantle Flow Coming From the Backside (Models F17 and F20)}

Reference model has been implemented by imposing kinematic boundary conditions in the mantle while the plate is maintained fixed with respect to the bottom of the box. In model F17, the piston is pushed

Figure 6. Trench kinematics (left) and evolution of trench position (right) for plates with (a) width of $660 \mathrm{~km}$, (b) width of 2,000 km, and (c) width of $4,000 \mathrm{~km}$. (d) Trench velocity averaged along the trench as a function of time for the three models (solid lines). The dashed lines indicate the velocities recorded at the center of the subduction zone and the dotted lines at the edges of the subduction zone. (e) Trench curvature evolution during subduction as measured (i) over the entire trench length as the ratio between the maximum horizontal distance along the $x$-axis of the trench $(h)$ over the width of the trench ( $W$ ), as indicated by dots or (ii) only over the first $660 \mathrm{~km}$ from the edges of the subduction zone, as indicated by diamonds. Positive curvature values indicate that the trench is concave toward the backside of the subduction zone. 
producing an homogeneous mantle flow coming horizontally from the backside at $0.9 \mathrm{~mm} / \mathrm{min}(\sim 0.9 \mathrm{~cm} /$ $\mathrm{yr})$, that is, around $40 \%$ and $66 \%$ of the spontaneous trench rollback velocity in the center and at the edges of the reference model, respectively. In model F20, a two-fold increase of piston velocity is imposed (1.8 mm/ min corresponding to $\sim 2 \mathrm{~cm} / \mathrm{yr}$ in nature), that is, in between the spontaneous trench retreat velocity at the center and at the edges of the subduction zone.

\subsubsection{Kinematics and Trench Curvature}

The impact of imposed background flow on trench kinematics is two-fold (Figure 8). First, imposing an additional driving force by moving the mantle toward the foreside of the subduction zone increases trench roll back velocity during the steady state phase along the entire subduction zone. At the center of the subduction zone, the steady-state trench velocity is $12 \%$ (model F17) and 30.5\% (model F20) higher than that in the reference model (Figures 3 and 8). At the edges of the subduction zone, the difference is more pronounced with an increase of 63\% (model F17) and 101.5\% (model F20) with respect to that in the reference model (Figure 8). However, observed trench velocity is not exactly the sum of spontaneous trench roll back velocity and mantle flow velocity. In the center of the subduction zone, for instance, observed trench retreat velocity represents only $70 \%-80 \%$ of the theoretical velocity (Figure 9 ). It means that part of the additional driving force produced by viscous mantle flow is dissipated elsewhere in the system.

Second, an imposed background mantle flow coming from the backside smooth the lateral trench velocity variability. The center to edge velocity ratio during steady state is 1.7 in the reference model whereas it is only 1.2 in model F17 and 1.12 in model F20. The trench curvature increases linearly with the amount of subduction, similar to that observed in the reference model without background flow (Figure 10). However, the trench concavity is less marked with a two-fold decrease of the trench curvature when increasing the mantle flow from 0 to $2 \mathrm{~cm} / \mathrm{yr}$ after $\sim 1,200 \mathrm{~km}$ of subduction (Figure 10f).

\subsubsection{Mantle Flow and Deformation}

Mantle flow around the subduction zone in the models results from the interaction between the imposed background mantle flow and slab-induced mantle flow. As a consequence, after the same amount of subduction, the pattern of instantaneous mantle flow largely differs from the reference model (Figure 11). Indeed, the entire mantle flow is directed toward the foreside of the subduction zone even if deflected at slab edges where return flow is observed for the reference model (Figure 4c). The deflection is less pronounced when background flow velocity is increased by a factor of 2 (Figure 11b). The associated instantaneous mantle strain field during the steady-state subduction does not significantly differ from the reference model in terms of maximum strain rate that also approaches $\sim 1-1.5 \times 10^{-15} \mathrm{~s}^{-1}$ for both moderate and high background flows (Figure 12). However, and as already observed with mantle flow, strain at the slab edges slightly differs from the reference model. Strain rates for the direction of maximum extension is around $1 \times 10^{-15} \mathrm{~s}^{-1}$ at distances up to $500 \mathrm{~km}$ from the slab edges, whereas it is under $0.5 \times 10^{-15} \mathrm{~s}^{-1}$ in the reference model. The width of the region of mantle stirred almost perpendicularly $\left(90 \pm 20^{\circ}\right)$ to the trench direction above the slab also increases with increasing background flow from $\sim 1,000$ to $\sim 1,300 \mathrm{~km}$.

\subsubsection{Slab Dip}

Due to technical constraints, we can only image the geometry of the slab in the vertical plane at one edge of the subduction zone. However, mantle flow is mostly disturbed at slab edges when imposing background flow, and as such, this is where the most significant changes in slab geometry in the vertical plane are expected. Figure 13 shows the shape of the top of the slab with corresponding measurements of slab dip as a function of depth for the reference model and for models with background flow coming from the backside. Overall, slab geometry in the vertical plane is almost similar, as variations in slab dip do not exceed $12^{\circ}$. The largest variations are observed at mid-upper mantle depths where models with background flow exhibit steeper slabs.

For depths lower than $300 \mathrm{~km}$, the model with moderate background flow coming from the backside maintains a slab dip slightly larger by $\sim 5^{\circ}$ than that of the reference model. Instead, the model with high background flow has dip values that become close to those of the reference model, close to the surface. While the geometry of the slab in the vertical plane may appear non-linear with increasing background flow, there is a systematic increase in the difference between dip at the mid-upper mantle depth and dip at $z=-50 \mathrm{~km}(\Delta \beta$; 

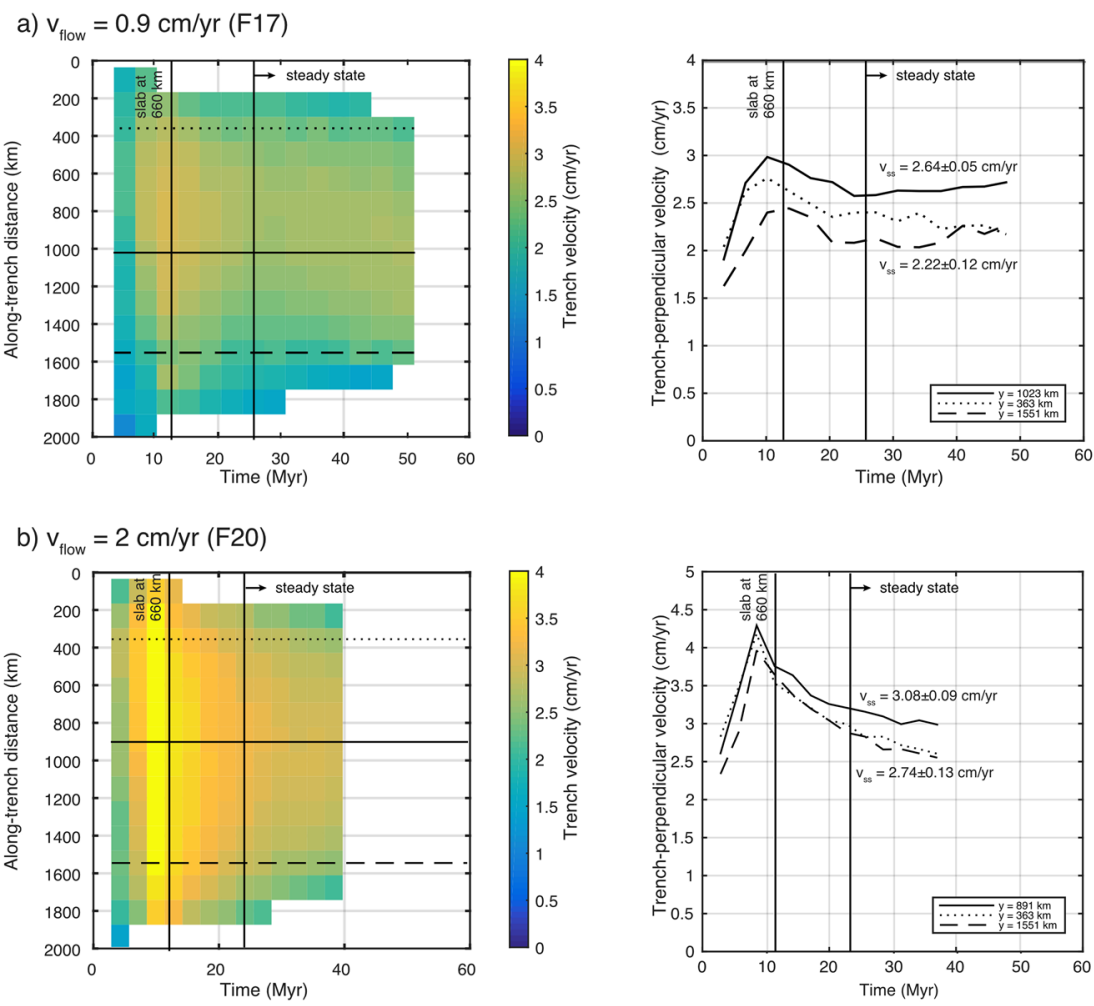

C) $\mathrm{v}_{\text {flow }}=-1.2 \mathrm{~cm} / \mathrm{yr}$ (F24)
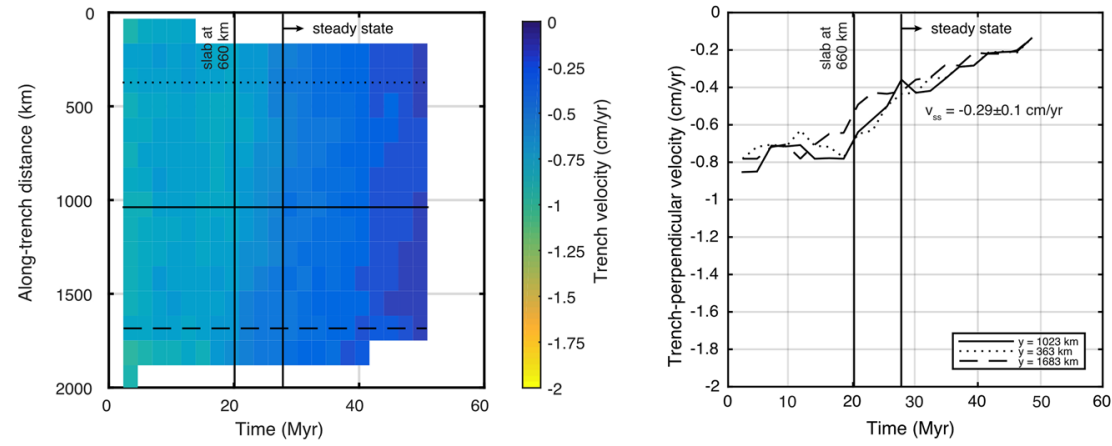

d) $\mathrm{v}_{\text {flow }}=-2.7 \mathrm{~cm} / \mathrm{yr}(\mathrm{F} 26)$
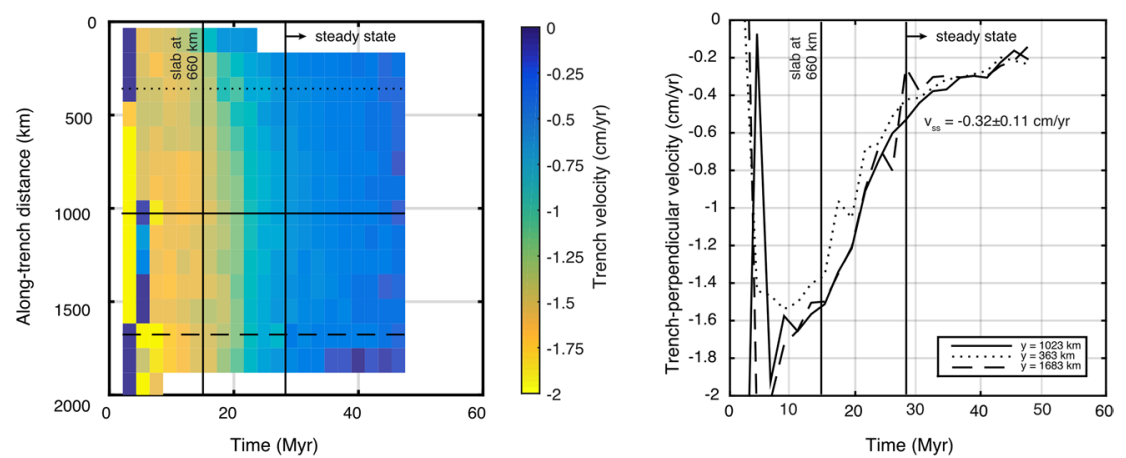


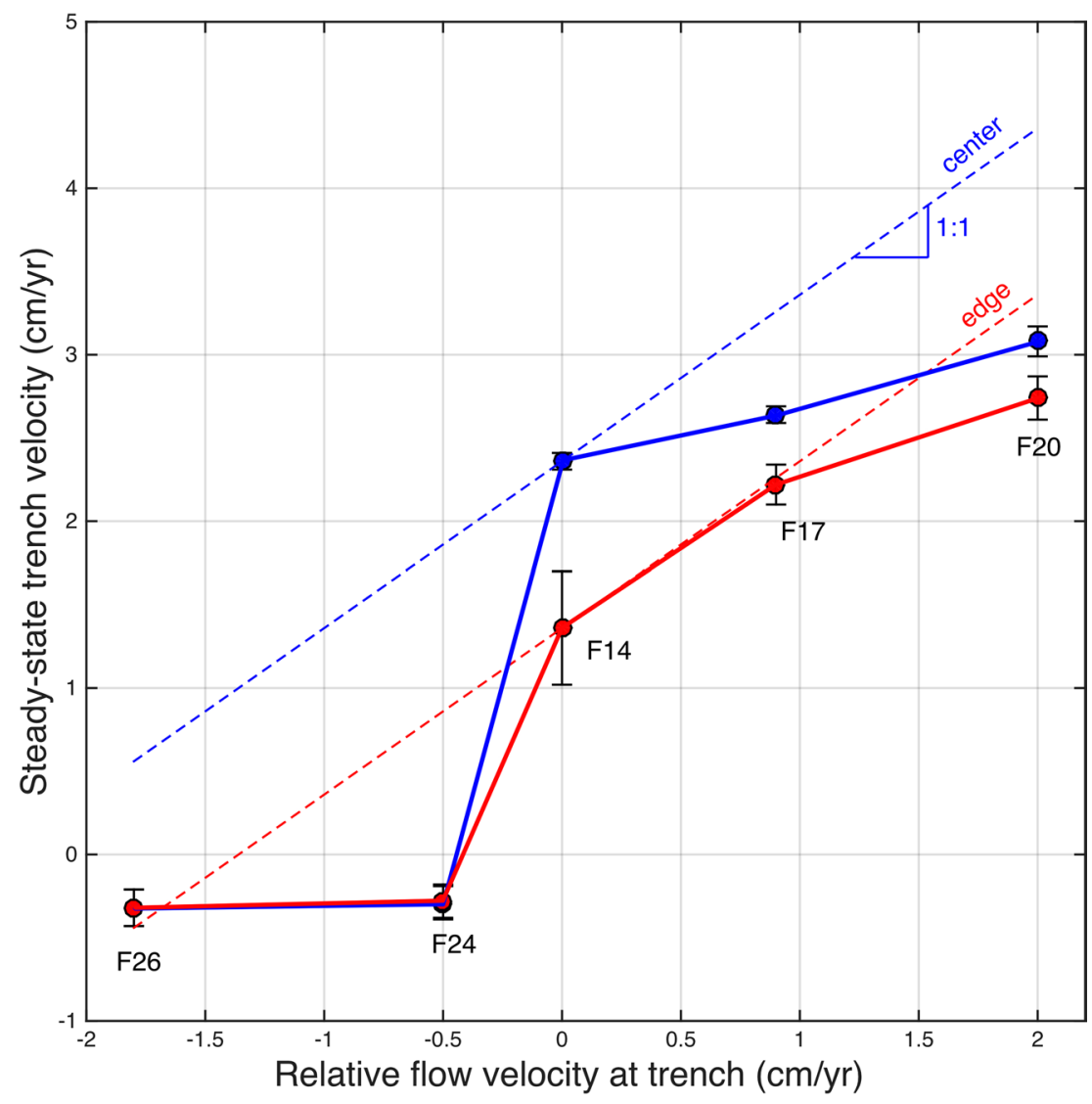

Figure 9. Steady-state trench velocity as a function of imposed relative flow velocity between the mantle and the subducting plate in the center (blue dots) and at the edges (red dots) of the subduction zone. Trench and mantle motions toward the foreside of the subduction zone are taken as positive. Dashed lines indicate the theoretical trench velocity that would result from the addition of spontaneous trench motion and imposed mantle displacement rate.

Figure 13e). It goes from $28^{\circ}$ for the reference model to $31^{\circ}$ for $v_{\text {flow }}=0.9 \mathrm{~cm} / \mathrm{yr}$ and $40^{\circ}$ for $v_{\text {flow }}=2 \mathrm{~cm} / \mathrm{yr}$, the background flow exerting additional pressure that results in a larger shear of the slab.

\subsection{Models With Mantle Flow Coming From the Foreside (Models F24 and F26)}

Reference model has been implemented by imposing new kinematic boundary conditions in the mantle. In model F24, the piston is pushed producing a homogeneous mantle flow coming horizontally from the foreside at $0.8 \mathrm{~mm} / \mathrm{min}(\sim 1.2 \mathrm{~cm} / \mathrm{yr})$, that is, around $50 \%$ and $88 \%$ of the spontaneous trench rollback velocity in the center and at the edges of the reference model, respectively. In model F26, a two-fold increase of piston velocity is imposed $(1.8 \mathrm{~mm} / \mathrm{min}$ corresponding to $\sim 2.7 \mathrm{~cm} / \mathrm{yr}$ in Nature), that is, around $15 \%$ faster than the spontaneous trench retreat velocity at the center of the subduction zone. However, in these models, the coupling between the convective mantle and the subducting plate results in significant deformation of the horizontal part of the plate, which was not observed in models with mantle flow coming from the backside. Indeed, for model F24, for instance, mantle drag at the base of the horizontal portion of the plate induces its horizontal deformation in the trench-perpendicular direction at average rates of at least $8 \times 10^{-17} \mathrm{~s}^{-1}$, taking into account only the lateral shrinkage of the plate and not its potential thinning. The

Figure 8. Trench kinematics for the models with mantle flow coming from the backside at (a) $0.9 \mathrm{~cm} / \mathrm{yr}$ (model F17) and (b) $2 \mathrm{~cm} / \mathrm{yr}$ (model F20) and from the foreside at (c) $-1.2 \mathrm{~cm} / \mathrm{yr}$ (model F24) and (d) $-2.7 \mathrm{~cm} / \mathrm{yr}$ (model F26). Left panels show the evolution of trench velocity (color map) as a function of time and along-trench distance. Note the differences for the color map in between models F17-F20 and models F24-F26. Trench motion toward the foreside of the subduction zone is considered positive. Right panels show the time evolution of trench velocity in the center (solid line) and at the edges of the subduction zone (dotted and dashed lines). Precise locations of the profiles are indicated on Figure 8a. 
a) $\quad \mathrm{v}_{\text {flow }}=0 \mathrm{~cm} / \mathrm{yr}(\mathrm{F} 14)$

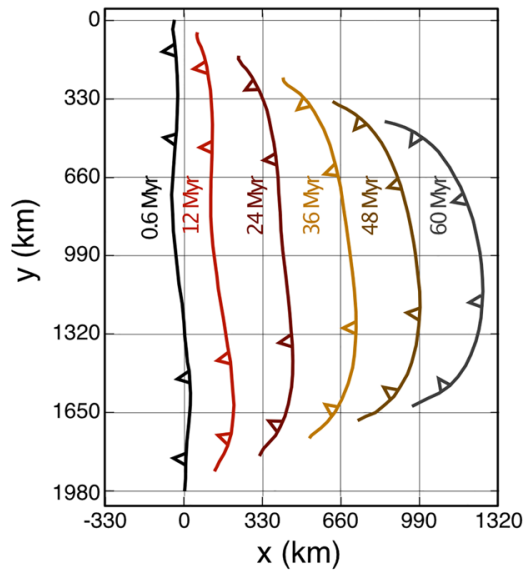

d) $\mathrm{v}_{\text {flow }}=-1.2 \mathrm{~cm} / \mathrm{yr}(\mathrm{F} 24)$

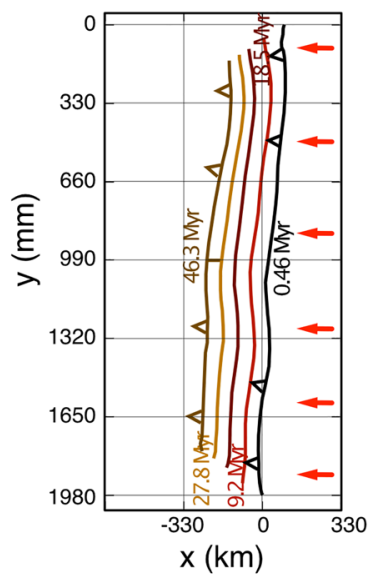

b) $\quad \mathrm{v}_{\text {flow }}=0.9 \mathrm{~cm} / \mathrm{yr}(\mathrm{F} 17)$

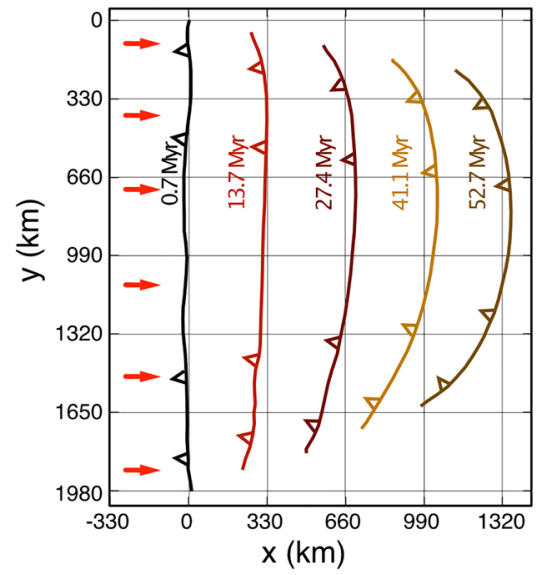

e) $\mathrm{v}_{\text {flow }}=-2.7 \mathrm{~cm} / \mathrm{yr}(\mathrm{F} 26)$

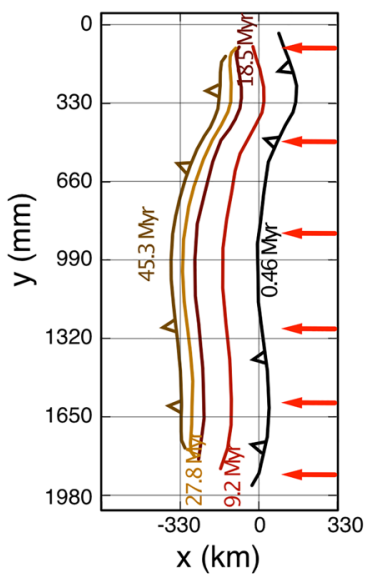

c) $\quad \mathrm{v}_{\text {flow }}=2 \mathrm{~cm} / \mathrm{yr}(\mathrm{F} 20)$

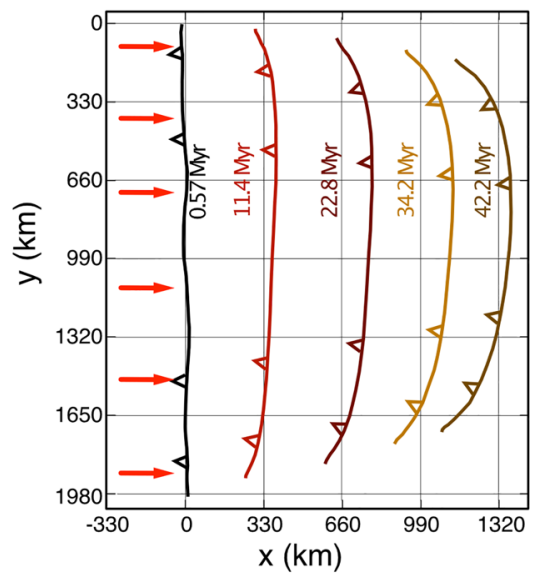

f)

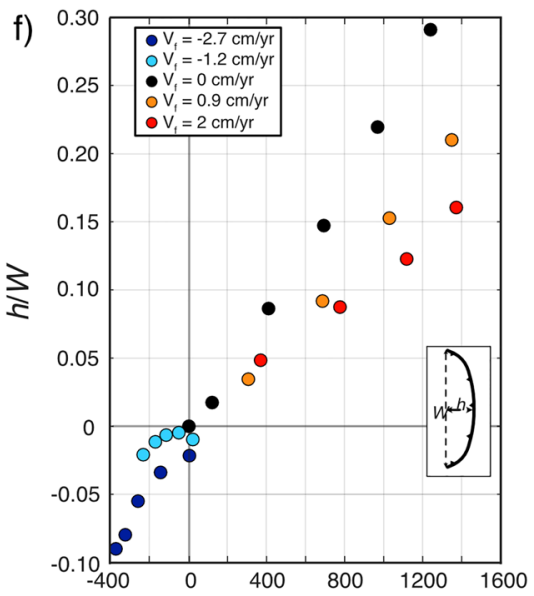

Amount of trench displacement $(\mathrm{km})$

Figure 10. Evolution of the trench position during subduction for (a) reference model ( $\left.v_{\text {flow }}=0 \mathrm{~cm} / \mathrm{yr}\right),(\mathrm{b}) \operatorname{model~F17}\left(v_{\text {flow }}=0.9 \mathrm{~cm} / \mathrm{yr}\right),(\mathrm{c}) \mathrm{model} \mathrm{F} 20$ $\left(v_{\text {flow }}=2 \mathrm{~cm} / \mathrm{yr}\right),(\mathrm{d})$ model F24 ( $\left.v_{\text {flow }}=-1.2 \mathrm{~cm} / \mathrm{yr}\right)$, (e) model F26 ( $\left.v_{\text {flow }}=-2.7 \mathrm{~cm} / \mathrm{yr}\right)$. (f) Trench curvature evolution as a function of the amount of trench motion. Trench displacement toward the foreside of the subduction zone is considered as positive. Curvature is measured over the entire trench length as the ratio between the maximum horizontal distance along the $x$-axis of the trench $(h)$ over the width of the trench $(W)$. Positive curvature values indicate that the trench is concave toward the backside of the subduction zone.

trailing edge of the subducting plate is fixed and therefore, has a zero velocity, while the average absolute velocity of the leading edge of the plate before subducting is at least $0.7 \mathrm{~cm} / \mathrm{yr}$. So, the relative velocity between the plate and the imposed background flow in model F24 is indeed of $-1.2 \mathrm{~cm} / \mathrm{yr}$ at the trailing edge of the plate, but it is $-0.5 \mathrm{~cm} / \mathrm{yr}$ or lower at the trench. For model F26, the relative velocity is $-2.7 \mathrm{~cm} / \mathrm{yr}$ at the trailing edge of the plate and $-1.8 \mathrm{~cm} / \mathrm{yr}$ at the trench.

\subsubsection{Kinematics and Trench Curvature}

Mantle flow coming from the foreside induces a profound change in the subduction kinematics. Indeed, additional background flow coming from the foreside does not only slow down the trench velocity by opposing the retrograde motion of the slab, but also promotes trench advancing (Figures $8 \mathrm{c}$ and $8 \mathrm{~d}$ ). Since the subducting plate is fixed at its trailing edge, trench advance is only made possible by the fact that the horizontal part of the subducting plate deforms because of mantle drag (see above). Control of the background flow on trench kinematics is pretty obvious in the first stage of the subduction process. Indeed, for the first $10 \mathrm{Myr}$, the measured trench advance velocity is twice as high as that in the model with large mantle flow coming from the foreside $(-1.7 \pm 0.1 \mathrm{~cm} / \mathrm{yr}$ in model F26) than that in the model with less vigorous mantle flow $(-0.85 \pm 0.1 \mathrm{~cm} / \mathrm{yr}$ in model F24) (Figures $8 \mathrm{c}$ and $8 \mathrm{~d}$ ). After the slab has reached the 660-km discontinuity, 

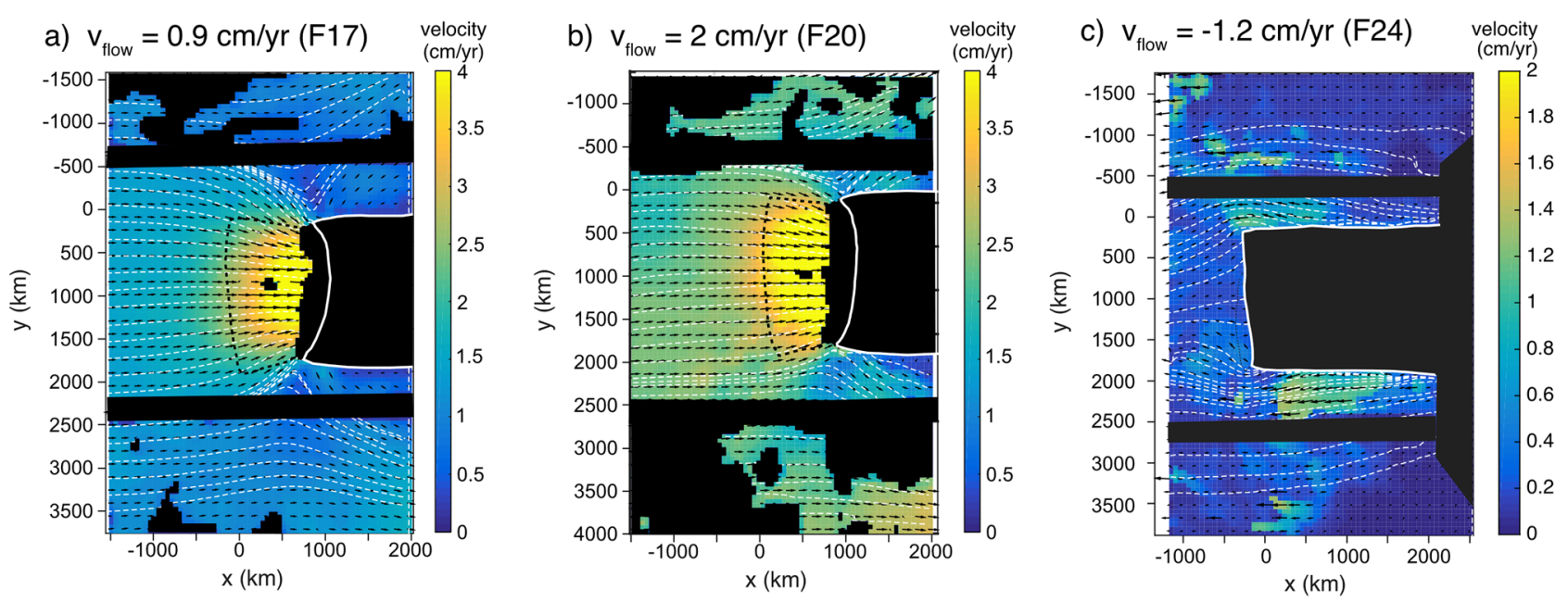

Figure 11. Instantaneous horizontal mantle flow for (a) model F17 after $40 \mathrm{Myr}$ ( 1,000 km) of subduction, (b) model F20 after $31 \mathrm{Myr}$ ( $\sim 1,000 \mathrm{~km})$ of subduction, and (c) model F24 after 40 Myr of subduction. Note the difference in the colorbar for model F24. The top views do not encompass the entire modeled domain. Streamlines are displayed with white dashed lines. Black areas correspond to zones with poorly resolved image correlation.

the imposed background flow still controls the trench kinematics, forcing trench advance, but the influence of the magnitude of the mantle flow becomes negligible as both models show a trench velocity that stabilizes at $\sim 0.3 \pm 0.1 \mathrm{~cm} / \mathrm{yr}$ (Figures 8 and 10). Again, during the steady-state phase of subduction, the relationship between trench kinematics and background mantle flow is not straightforward. For model F24, the relative velocity between spontaneous trench motion (retreat at $1.4 \mathrm{~cm} / \mathrm{yr}$ at the edges and $2.4 \mathrm{~cm} / \mathrm{yr}$ in the center), and the imposed background mantle flow at the trench $(-0.5 \mathrm{~cm} / \mathrm{yr})$ should be in the range $0.9-1.9 \mathrm{~cm} / \mathrm{yr}$, that is, the trench should be retreating. Instead, the trench is advancing at rates of around $0.3 \mathrm{~cm} / \mathrm{yr}$ during steady-state subduction (Figure 9). It means that the force equilibrium that controls trench kinematics in the reference model is deeply affected by the additional viscous mantle drag in a non-linear way. In model F24, the center to edge velocity ratio during the steady-state is very close to unity (1.04), resulting in a trench shape that becomes slightly convex toward the backside of the subduction zone over time with values up to 0.02 (Figure 10f). This convexity increases with increasing background flow velocity, reaching values of 0.09 after $370 \mathrm{~km}$ of trench advance in model F26 (Figure 10f). However, because the initial convexity is already of 0.02 , the change in convexity in this model is only of 0.07 .

\subsubsection{Mantle Flow and Deformation}

The pattern of mantle flow is largely controlled by the background mantle flow coming from the foreside that counteracts the natural tendency of the slab to retreat. Indeed, the mantle flows toward the backside of the subduction zone everywhere in the model, including the area located above the slab, in a direction sub-parallel with that of the background flow (Figure 11). Only at the slab edges the flow exhibits local variations in terms of direction and magnitude. This is the place where the largest velocities are recorded (up to $1.5 \mathrm{~cm} / \mathrm{yr}$ ), as the mantle material has to flow around the slab edges. Velocities larger than the background flow indicate that at slab edges up to $20 \%$ of the flow directed toward the backside of the subduction zones results from the buoyancy-driven subduction of the slab.

In terms of mantle strain, the large trench-perpendicular stretching that was recorded above the subducting lithosphere, for both the reference model and the models with background flow coming from the backside, is no longer present (Figure 12c). Indeed, mantle flow that comes from the foreside is deviated by the slab, creating a shadow zone with almost no deformation behind. In addition, background flow prevents the slab from retreating, which also controls trench-perpendicular stretching, as evidenced in the reference model. Only on restricted zones at the slab edges, where the slab-driven flow interacts with the background flow, strain rates are slightly larger, up to $0.5-1 \times 10^{-15} \mathrm{~s}^{-1}$. 
a) $\mathrm{v}_{\text {flow }}=0.9 \mathrm{~cm} / \mathrm{yr}(\mathrm{F} 17)$

$\mathbf{e}_{\max }$

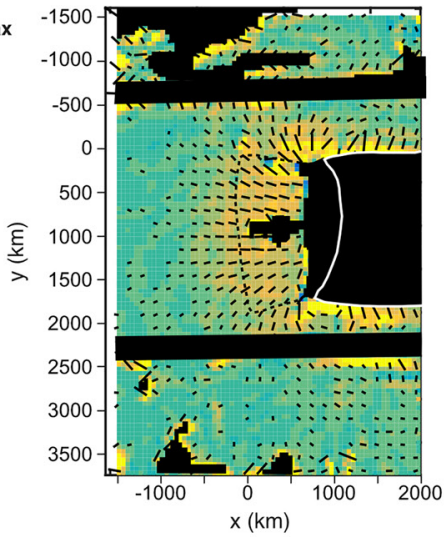

$\mathbf{e}_{\min }$

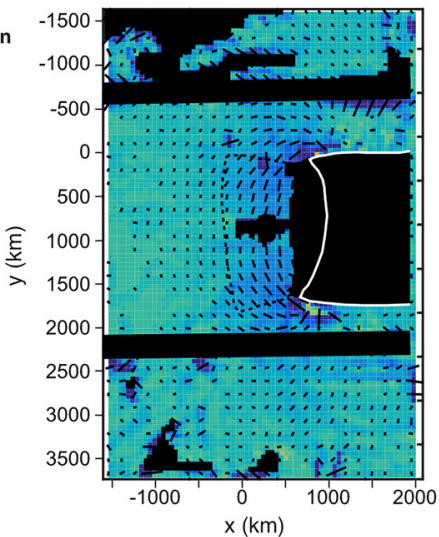

azimuth of $\mathbf{e}_{\max }$

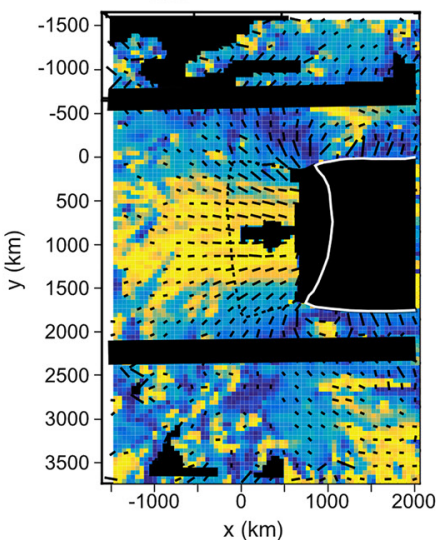

b) $\mathrm{v}_{\text {flow }}=2 \mathrm{~cm} / \mathrm{yr}(\mathrm{F} 20)$
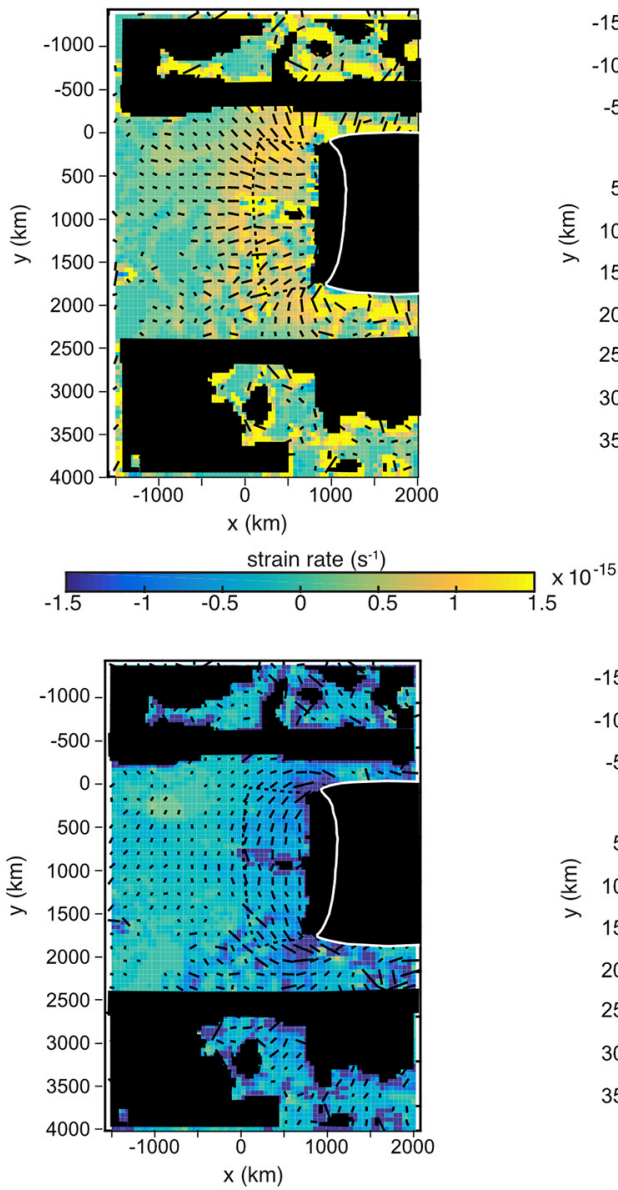

strike

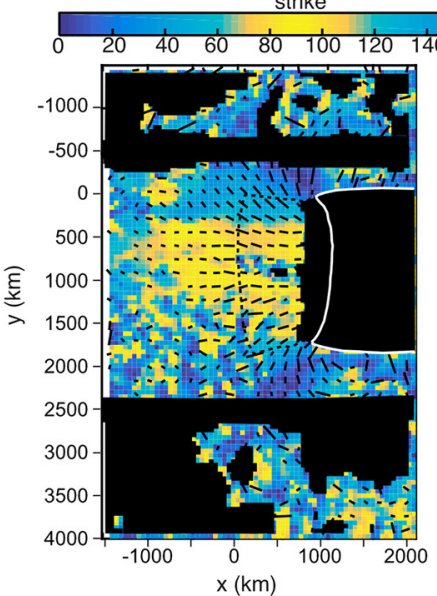

c) $\mathrm{v}_{\text {flow }}=-1.2 \mathrm{~cm} / \mathrm{yr}(\mathrm{F} 24)$

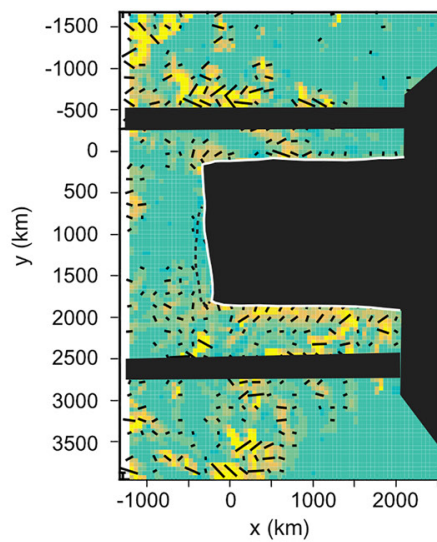

$\times 10^{-15}$
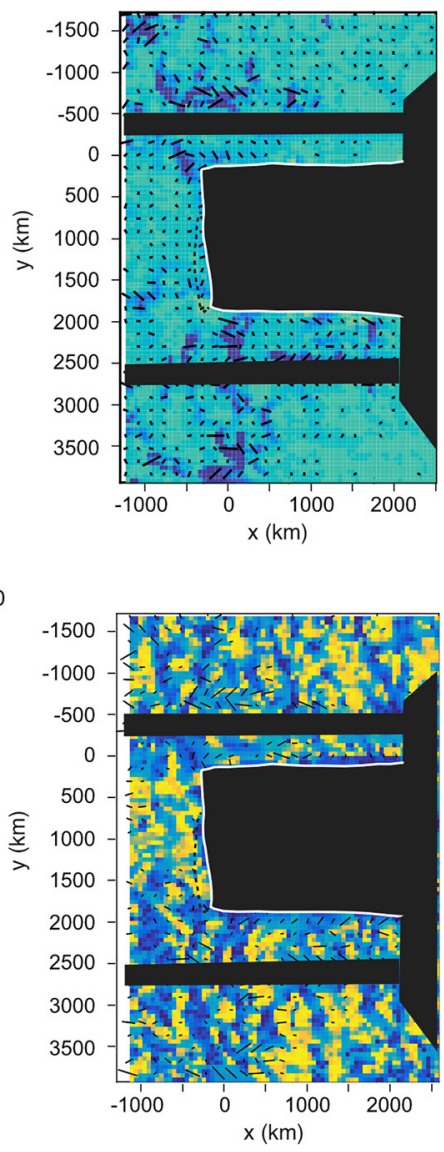

Figure 12. Magnitude and orientation of the axes of the infinitesimal horizontal strain ellipse with extension axis (top), shortening axis (center), and azimuth of the extension axis (bottom) for (a) model F17 after $40 \mathrm{Myr}(\sim 1,000 \mathrm{~km})$ of subduction, (b) model F20 after 31 Myr ( 1,000 km) of subduction, and (c) model F24 after 40 Myr of subduction. 

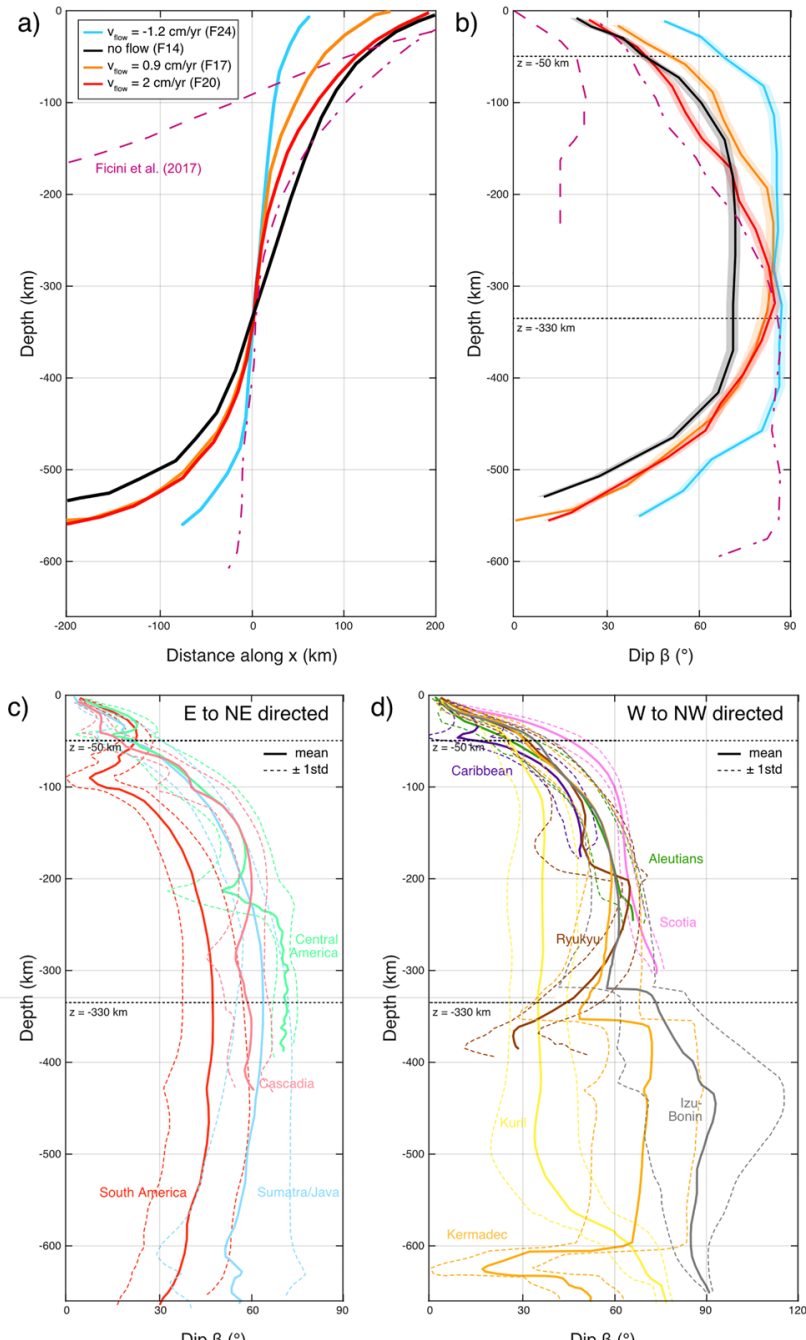

$\operatorname{Dip} \beta\left(^{\circ}\right.$

$\operatorname{Dip} \beta\left(^{\circ}\right)$

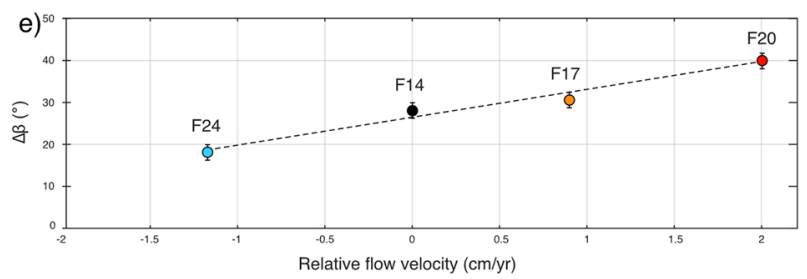

Figure 13. (a) Position of the top of the slab at the edge of the subduction zone during steady-state subduction as a function of depth. The curves on the left are all aligned so that $x=0 \mathrm{~km}$ when $z=330 \mathrm{~km}$. Profiles from Figure 2 of Ficini et al. (2017) are shown in pink. (b) Corresponding slab dip. (c) Slab dip profiles extracted from the Slab 2.0 database (Hayes et al., 2018) for present-day subduction zones dipping toward the East and North-East. The solid line indicates the mean value and the dashed lines 1 standard deviation. (d) Same as (c) for slabs dipping toward the West and North-West. (e) Difference in slab dip measured in the models in between $z=-50 \mathrm{~km}$ and $z=-330 \mathrm{~km}$ as a function of the imposed relative flow velocity between the mantle and the slab.

\subsubsection{Slab Dip}

Slab dip is also only measured for model F24 at one edge of the subduction zone due to technical constraints. Given the low variability in trench kinematics along the trench, we expect the slab dip to be fairly constant along the subduction zone, and the external profile to be representative of the entire subduction zone. Model F24 shows a larger dip with respect to the reference model at every depth, with deviations between $15^{\circ}$ and $30^{\circ}$ (Figure 13). In particular, slab dip exceeds $80^{\circ}$ for a large range of depths (80-450 km). While exhibiting larger dips, the variation of slab dip between mid-mantle depth and $z=-50 \mathrm{~km}(\Delta \beta$; Figure 13e $)$ is lower than that in the reference model $\left(18^{\circ}\right.$ vs. $\left.28^{\circ}\right)$.

\section{Discussion}

We use three-dimensional analog models of subduction to explore how plate width and "regional" horizontal mantle flow affect (a) the pattern of horizontal mantle flow around subduction zones, (b) the trench kinematics and curvature, and (c) the geometry of the slab in the vertical plane. For a fixed ridge configuration, in the absence of an imposed background flow, slab pull initially controls the subduction velocity, which corresponds to trench velocity, since internal deformation of the horizontal portion of the subducting plate is negligible. We, therefore, prevent possible subducting plate motion during subduction, and as such, the obtained trench velocities may be seen as maximum values. Indeed, Strak and Schellart (2016) show with an almost similar set-up but including a free trailing edge that the subducting plate velocity can account for $16 \%-33 \%$ of the subduction velocity for the corresponding range of plates' widths, the rest being accommodated by trench retreat. In our models, trench retreat is accommodated by a combination of poloidal and toroidal flows around the slab edges.

\subsection{Subduction-Induced Flow Controlled by Slab Width}

Changing the width $(W)$ of the subducting plate modifies the subduction-induced mantle flow, which in turn changes the trench kinematics and shape. The effect of plate width has been previously studied by means of 3D numerical and analog models (Funiciello et al., 2006; Li et al., 2014; Schellart et al., 2007; Stegman et al., 2006; Strak \& Schellart, 2016), which showed that trench retreat velocity during the steadystate stage of subduction decreases with increasing plate width, as the mantle has to travel a larger distance to flow around the slab from the foreside to the backside. It has been proposed that trench motion could be almost null in the center of a 6,000-km wide subduction zone (Schellart et al., 2007), a result that we do not observe in our 4,000-km wide model. The discrepancy may come from the boundary conditions applied to the subducting plate, the plate being fixed in our case, which forces the trench to retreat in order to accommodate subduction. In the models of Schellart et al. (2007), the trailing edge of the plate is free to move, which allows the plate to advance while the trench remains fixed.

At first-order, the curvature of the trench and its evolution over time also appears to depend on the width of the slab. Previous studies showed that the overall geometries for the trench can be split into the following: concave, sublinear, and convex toward the backside with increasing plate width (e.g., Strak \& Schellart, 2016). The transition between concave and 


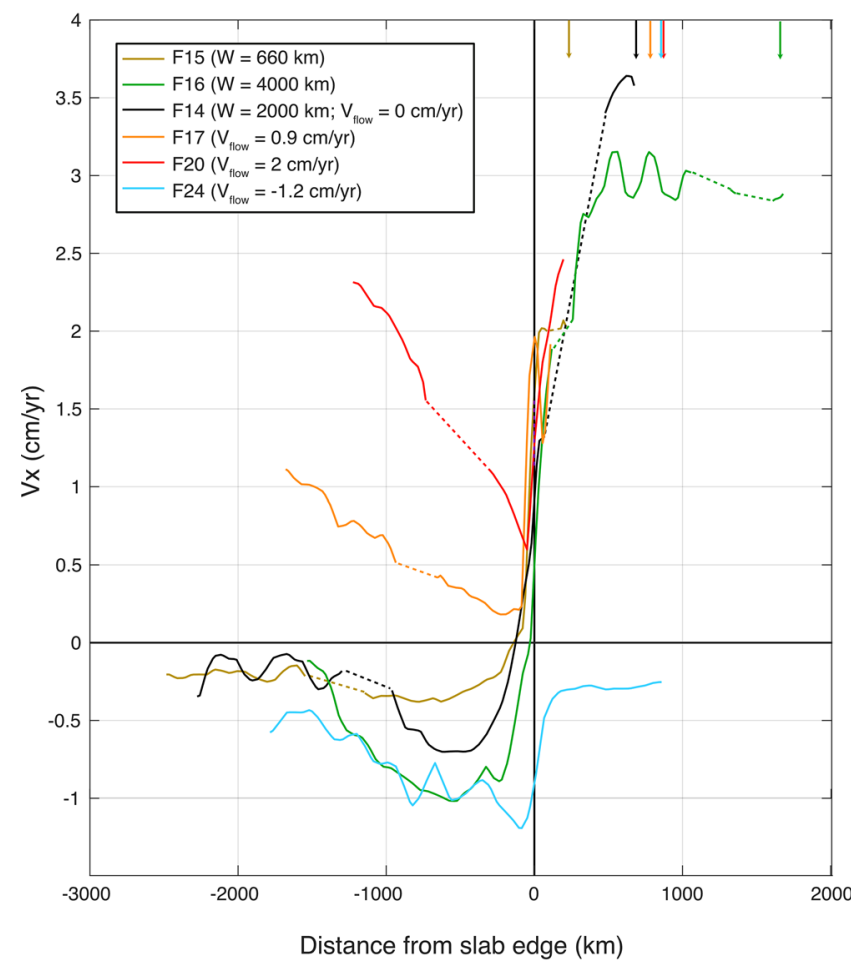

Figure 14. Velocity component $\mathrm{Vx}$ along a trench parallel profile along the $y$-axis. All curves are centered on 0 , which corresponds to the edge of the slab. Arrows at the top of the diagram indicate the location of the center of the plate. Dotted lines indicate segments with poorly resolved image correlation and correspond to a linear interpolation. sublinear modes was found at $\sim 2,000 \mathrm{~km}$ (Schellart et al., 2007; Strak \& Schellart, 2016) while in our study, the $2,000 \mathrm{~km}$ wide model exhibits a concave trench shape, at least after $\sim 40$ Myr (Figure $6 \mathrm{~b}$ ). The difference may come from the lower slab to mantle viscosity ratio used here (112-155 vs. 200-313), a lower viscosity ratio favoring trench curvature (Schellart, 2010). It has also been shown that the trench concavity is fairly constant for slabs widths in between 250 and 1,000-1,500 km while it decreases for higher widths (Morra et al., 2006; Strak \& Schellart, 2016). Here, we find that the transition also shifts toward higher slab widths, models with 660 and 2,000 km wide slabs sharing a common evolution with increasing concavity up to $40 \mathrm{Myr}$ (Figure 6e). Interestingly, after $40 \mathrm{Myr}$, the concavity of the $2,000 \mathrm{~km}$ wide model continues increasing at a faster rate than the $660 \mathrm{~km}$ model. For the 2,000 km wide model, it corresponds to the time where the two external parts of the trench, which exhibit concave shape from the beginning of the experiment, reunite as the slab narrows (Figure 6b). While the two models have an almost similar mean trench velocity, the lateral variation in trench velocity at that time is higher for the 2,000 km wide model, explaining the higher concavity. For the $4,000-\mathrm{km}$ wide slab, the geometry of the trench is more complex with the central portion of the slab exhibiting a convexity toward the backside of the subduction zone and two symmetric lateral lobes concave toward the backside (Figure 6). The convexity in the central part of the subduction zone results from the relative stagnation of the sub-slab mantle that limits trench retreat. However, the shape of the trench on the lateral edges of the three models appears to be almost similar. In particular, for the $2,000-\mathrm{km}$ wide and 4,000-km wide models, the maximum concavity during the entire subduction evolution is restricted to a region that spans over a distance of $\sim 600-700 \mathrm{~km}$ from each side of the subduction zone, similar to the thickness of the upper mantle. These areas show pretty close curvature values for all three models, which tend to reach a plateau over time with curvature of $\sim 0.2$ (Figure $6 \mathrm{e}$ ). This suggests that not only the width of the slab and the viscosity ratio between the slab and mantle (e.g., Funiciello et al., 2008; Morra et al., 2006) exert a control on the overall trench curvature, but also that the thickness of the convective layer (here, restricted to the upper mantle) controls the curvature of the subduction zone edges, in particular, for subduction zones larger than the thickness of the convective layer. In nature, where slabs can subduct into the lower mantle (e.g., Goes et al., 2008; Shephard et al., 2017), the thickness of the convective mantle may be larger, which may in turn increase the distance over which maximum curvature is observed.

We also map the mantle flow around the slab. In all models without background flow, the overall pattern is almost similar with two toroidal cells developing around the slab edges, as already evidenced in previous studies (e.g., Funiciello et al., 2006; Kiraly et al., 2017; Piromallo et al., 2006). We also show that the vigor of the mantle flow in the toroidal cells depends on the width of the plate, a larger plate promoting faster mantle flow at the slab edges (Figure 14), which is in agreement with results from Piromallo et al. (2006). On the other hand, there is no systematic change for the characteristic length of the toroidal cell with respect to slab width. All three models, spanning a range of widths of $660-4,000 \mathrm{~km}$, reach a plateau for the Vx component of the mantle velocity at around $-0.25 \pm 0.1 \mathrm{~cm} / \mathrm{yr}$ (i.e., directed toward the backside of the subduction zone) at distances of 1,000-1,500 km from the slab edge. Kiraly et al. (2017) obtained similar results, showing that while considering all other parameters constant, the length scale of the toroidal cell is not dependent on the width of the plate, but rather on the thickness of the convective mantle. For models with a similar mantle thickness $(660 \mathrm{~km})$ and plate width $(2,000 \mathrm{~km})$, the toroidal component starts to significantly decrease at $\sim 600-700 \mathrm{~km}$ from the slab edge, something that is also observed in our reference model (Figure 14). 


\subsection{Interactions Between Subduction-Induced and Background Flow}

During subduction, mantle flow induced by slab sinking may interact with a regional flow, that is, a flow resulting from slab-slab interactions (e.g., Kiraly et al., 2018), from sinking of an ancient detached slab (Coltice et al., 2019; Conrad \& Lithgow-Bertelloni, 2002; Ricard \& Vigny, 1989), in response to along-trench pressure gradients (Hall et al., 2000; Russo \& Silver, 1994), and/or from an "easterly" directed global mantle flow (e.g., Crespi et al., 2007; Cuffaro \& Doglioni, 2007; Ricard et al., 1991). Previous models have shown contrasted results on the effect of a horizontal background flow on the geometry of subducting lithosphere in the vertical plane. 2D or 2D-like models argue for an important effect of a background flow on the slab geometry in the vertical plane, associated with a modification of the subduction-induced poloidal flow (e.g., Boutelier \& Cruden, 2008). In particular, mantle flow coming from the backside of the subduction zone results in steep slabs, and mantle flow coming from the foreside in shallow dip (Ficini et al., 2017; Rodriguez-González et al., 2014) (Figure 13). Instead, results from 3D models show that the effect of a horizontal flow perpendicular to the trench direction is almost null (Chertova et al., 2018). We obtain similar results. The first-order geometry of the slab in the vertical plane in our models is only marginally affected by the background flow that is active prior to subduction initiation, whatever the direction and magnitude of the background flow (Figure 13). However, looking into details, one can make second-order observations:

1. The largest slab dips in the set of models we present are obtained for background flow coming from the foreside, which is at odds with 2D models where shallow slabs are observed. The large slab dip in our model can be explained by the fact that the background flow coming from the foreside induces trench advance (Figure 15). Analog models have shown that models with advancing trench generally exhibit larger dip than those with retreating trenches (e.g., Funiciello et al., 2003; Heuret et al., 2007). In addition, background flow coming from the foreside participates in the horizontal stretching and possible vertical plate thinning of the horizontal portion of the subducting plate prior to subduction. This would lead to a decrease of subducted plate thickness and associated slab pull force, which in turn would inhibit trench roll back and favor slab steepening during steady-state subduction, when the slab is anchored at the upper mantle-lower mantle transition.

2. The difference in slab dip $(\Delta \beta)$ between the near surface $(z=-50 \mathrm{~km})$ and mid-upper mantle depths linearly scales with the imposed relative flow velocity (Figure 13c). Mantle flow coming from the foreside generates a lower slab dip variability than mantle flow coming from the backside, with variations as large as $22^{\circ}$ within the range of imposed mantle flow. The slab adjusts its geometry to the forces acting on it to minimize the energy dissipation. At the steady-state, the only force that differs between the reference model and other models is the additional viscous force exerted on the surface of the slab by the mantle flow. To account for this change, the slab adjusts its geometry in the vertical plane by increasing/ decreasing its radius of curvature at the surface and at the $660-\mathrm{km}$ discontinuity, which modifies both the slab pull force that scales with the length of the slab and the slab bending resistance. For instance, the additional force resulting from mantle flow coming from the foreside, which favors subduction, is adjusted by a decrease of the slab pull and an increase of the bending resistance, which are obtained by decreasing the radius of curvature, that is, a steepening of the slab.

Overall, the adjustments in slab geometry in the vertical plane remain minor when compared to those observed in 2D. This outcome confirms the influence of the lateral boundary conditions on subduction dynamics. On Earth, previous studies have proposed that the present-day toroidal/poloidal ratio may be in the range $0.45 \pm 0.1$ (e.g., Becker, 2006; Lithgow-Bertelloni \& Richards, 1998), showing that the toroidal component of the mantle flow should not be neglected. This highlights the limitations of 2D and 2D-like models that do not take into account the toroidal component of mantle flow, and therefore enhance the effect of the poloidal component of mantle flow (Funiciello et al., 2004). When the third dimension is added in the modeled system, the background flow does not significantly deform the slab in the vertical plane despite the low viscosity ratio between the slab and mantle (112-155). Instead, the mantle is displaced and deformed around the slab. The force by unit length exerted by the mantle on the slab can be estimated in our models. Strain rates in the mantle close to the trench do not exceed $1.5 \times 10^{-15} \mathrm{~s}^{-1}$. Considering a mantle viscosity of $5 \times 10^{20} \mathrm{~Pa} \mathrm{~s}$, it gives a stress of $1.5 \mathrm{MPa}$, that once applied on the length of the slab $(550 \pm 50 \mathrm{~km})$ gives a force per unit length of $0.75-0.9 \times 10^{12} \mathrm{~N} / \mathrm{m}$. It is more than one order of magnitude lower than the slab pull force estimated for the same slab $\left(2.75-4.71 \times 10^{13} \mathrm{~N} / \mathrm{m}\right)$. Therefore, the influence of the background 
a)

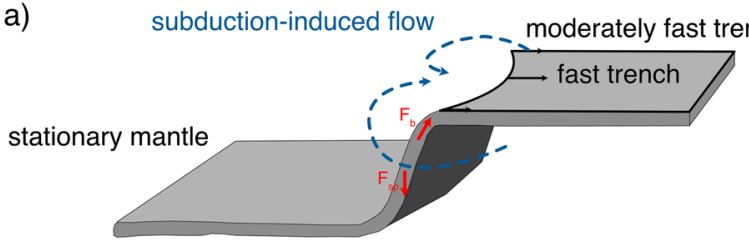

b) subduction-induced + background mantle flow

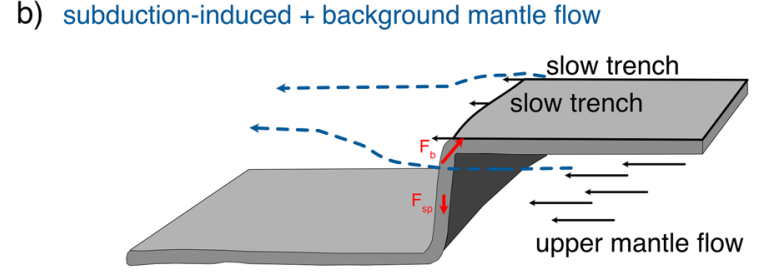

c) subduction-induced + background mantle flow

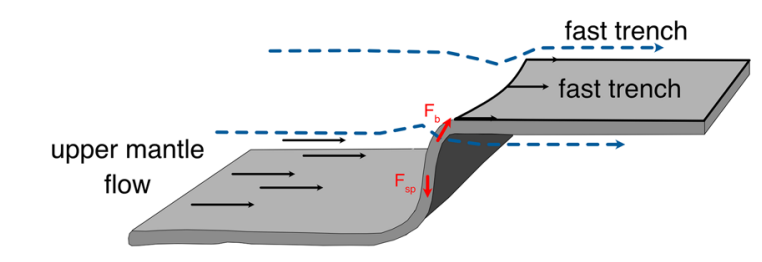

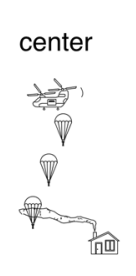

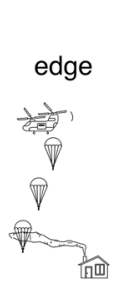

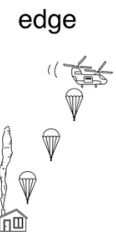

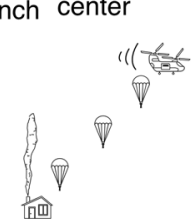

藏

edge

c)
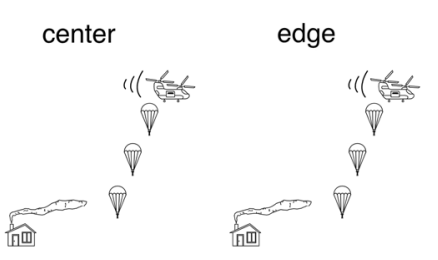

Figure 15. Sketches showing slab geometry, trench shape and superficial horizontal mantle flow for models with (a) no background flow, (b) background flow coming from the foreside of the subduction zone, and (c) background flow coming from the backside of the subduction zone (inspired by Tao \& O'connell, 1992). In the absence of background flow, the trench retreats faster in the center of the subduction zone, which results in a concave shape of the trench toward the backside and a steeper slab at edges. Application of a background flow tends to minimize lateral variations of trench kinematics, which results in a more linear trench, and almost-similar along-trench slab dip. The combination of trench motion and applied mantle flow results in a steeper slab for models with background flow than without. Red arrows indicate how slab pull force and slab bending force at trench evolve in models with background flow with respect to the reference model.

flow in 3D models may only be significant for subduction zones with low slab pull, that is, for oceanic plates with low plate thickness and/or low-density contrast with the mantle. A slab pull of around $10^{12} \mathrm{~N} / \mathrm{m}$ could only be obtained for non-eclogitized slabs with ages around $10 \mathrm{Ma}$ (Cloos, 1993). Further experiments are needed to quantify the effect of mantle flow with changing slab pull.

If the background flow only slightly modifies the slab geometry in the vertical plane, its impact on the trench horizontal shape is more significant (Figure 15). Mantle flow coming from both the foreside and backside tends to decrease the curvature of the trench. In models without background flow, slab rollback stirs the mantle that organizes into poloidal and toroidal cells. The flow exerts an overpressure at the edges of the slab that is high enough to limit the rate of trench rollback and deform the slab in the horizontal plane. In the case of mantle coming from the backside, the subduction-induced toroidal cells that developed around slab edges in the absence of the background flow to accommodate trench retreat do not exist anymore (Figures 11a and 11b). The imposed background flow promotes trench retreat at the slab edges and therefore, results in a less concave shape for the same amount of subduction (Figure 10f). The concavity of the trench directly depends on the magnitude of the background flow, with a trench curvature after around $1,200 \mathrm{~km}$ of trench retreat that is twice as low for a velocity magnitude of $2 \mathrm{~cm} / \mathrm{yr}$ than for the no-velocity model. In the case of mantle flow coming from the foreside, the formation of toroidal cells at slab edges is also prevented by the background flow, the direction of streamlines being almost parallel to the direction of the background flow (Figure 11c). The motion of the trench is dominated by the deformation of the horizontal portion of the subducting slab as a consequence of the basal drag exerted by the mantle. If the 
applied background flow has a magnitude that is close to the spontaneous trench retreat velocity (model F24), the combination of subduction-induced and imposed background mantle flows results in a trench that advances at a constant low rate along the subduction zone (Figure 10d). The trench curvature is, therefore, almost null with only a slight convexity toward the backside after $\sim 46 \mathrm{Myr}$ of subduction (230 km of trench advance) (Figure 10f). Instead, if the applied background flow has a magnitude larger than the spontaneous trench retreat (model F26), the trench advance becomes larger in the center of the subduction than at the edges ( $370 \mathrm{~km}$ vs. $335 \pm 10 \mathrm{~km}$ after $\sim 45 \mathrm{Myr}$ of subduction), resulting in a larger convexity toward the backside (Figures 10e and 10f).

Previous studies have proposed, on the basis of geophysical data, that a global or net westward drift of the lithosphere relative to the mantle (e.g., O'Connell et al., 1991; Ricard et al., 1991) occurs on Earth, which implies a relative opposed flow of the convective mantle, sometimes referred to as "mantle wind" in the literature (e.g., Crespi et al., 2007; Doglioni et al., 2015). It may be made possible by the presence of a weak zone at the LAB, allowing a decoupling between the asthenosphere and the lithosphere and their relative motion (e.g., Becker, 2017; Doglioni et al., 2011). However, previous attempts of modeling have generally failed at taking into account this relative motion. Because of the chosen boundary conditions, the plate is generally free to move with the convective mantle (Ficini et al., 2017) or its motion is imposed by pushing the subducting plate at a constant velocity (Boutelier \& Cruden, 2008; Chertova et al., 2018; Rodriguez-Gonzales et al., 2014; Van Hunen et al., 2000). As a consequence, for certain of these models the applied boundary conditions result in a relative motion between the plate and the underlying mantle that is opposite to the one initially considered. In the study by Rodriguez-Gonzales et al. (2014) for instance, the subducting plate is pushed toward the trench at a constant velocity of $8 \mathrm{~cm} / \mathrm{yr}$ while the imposed background flow varies between $-4 \mathrm{~cm} / \mathrm{yr}$ and $4 \mathrm{~cm} / \mathrm{yr}$. It implies that for models with flow coming from the foreside, the relative motion between the subducting plate and the underlying mantle is $4 \mathrm{~cm} / \mathrm{yr}$ instead of $-4 \mathrm{~cm} / \mathrm{yr}$. Therefore, the effect of the relative mantle flow on the slab geometry in the vertical plane cannot be directly extracted from these experiments. Instead, in our study, by fixing the velocity of the subducting plate, we control the relative mantle flow. However, with models with mantle flow coming from the foreside, this relative motion is not homogeneous along the horizontal portion of the plate as the plate is horizontally stretched. Such phenomena could be reduced by introducing a low-velocity zone beneath the plate. However, Ficini et al. (2017) showed that the presence of a low viscosity layer $\left(10^{18} \mathrm{~Pa} \mathrm{~s}\right)$ between the depths of 100 and $200 \mathrm{~km}$ does not modify substantially the geometry of the slab in the vertical plane, with respect to models without weak zone at the LAB. We, therefore, expect only second-order changes to the results presented here.

\subsection{Application to Nature}

Despite the aforementioned limitations, it is tempting to extract from these models first-order information that may help to interpret subduction zones dynamics. Our models confirm that both the mean trench velocity and the variability of trench velocity along subduction zones are sensitive to the width of the subducting plate (e.g., Funiciello et al., 2006; Guillaume et al., 2010; Li et al., 2014; Schellart et al., 2007). Narrow slabs have a faster trench retreat and exhibit a lower trench velocity variability along the subduction zone. In the case of a stationary or slowly moving overriding plate, it may translate into an upper plate extensional regime with homogeneous strain rates along the subduction zone. Instead, for very large plates with the same conditions, extension in the overriding plate may be more limited and some lateral variations in the deformation regime may occur. If the overriding plate moves toward the trench, shortening may develop within the overriding plate (e.g., Cerpa et al., 2018; Guillaume et al., 2018), which in the case of a large plate may produce a large variability in the amount of shortening. This is what has been proposed, for instance, to explain the large differences in the amount of shortening in the Andes, the large width of the Nazca plate inducing a larger amount of shortening in the center of the subduction zone (Russo \& Silver, 1996). Further testing by adding to the current setup an overriding plate and a moving subducting plate is planned in a future experimental step.

Seismic anisotropy represents a useful tool to shed light on the mantle flow and, in turn, on the dynamics of convergent margins. Looking at the patterns of mantle circulation characterizing worldwide subduction zones (e.g., Long \& Silver, 2008, 2009), first order characteristics arise. Fast directions are generally trench 
parallel in the fore-arc, turn around the edges of the slab and become trench perpendicular in the wedge. However, the geodynamical interpretation of this setting is not straightforward because seismic anisotropy samples different possible sources.

While the prevailing control on seismic anisotropy has been recognized to develop from subduction-induced mantle flow (e.g., Russo \& Silver, 1994), other ingredients like serpentinized aligned cracks in the shallow lithosphere (Faccenda et al., 2008), or B-type olivine, or serpentinite fabric in the cold corner of the mantle wedge (e.g., Nakajima \& Hasegawa, 2004) have been invoked. Our reference model, in the absence of external velocity boundary conditions confirms that the subduction kinematics plays a key role in defining seismic anisotropic imprinting: subduction and trench rollback are accommodated by two symmetrical toroidal cells with flow coming from the foreside to the backside area. Our results showed how the slab width tunes the trench velocity which also affects the strength of mantle circulation and, in turn, the time delay, $\delta t$, between the arrival of the fast and slow wave components (e.g., Long \& Silver, 2009). This is a well-recognized feature in global subduction zones with extreme cases represented by narrow subductions like Sandwich, Caribbean, Calabria and wide ones like South America, Sumatra and Aleutians.

However, our models have shown that the background mantle flow-whatever its engine-can locally increase the complexity of mantle circulation enhancing the development of multiple fast directions and preventing the formation of toroidal cells at slab edges. This contribution could be significant in convergent margins characterized by low trench velocities (e.g., Cascadia) or by tectonically most complex regions (e.g., Northern Sulawesi, the Molucca Sea, Sangihe; e.g., Di Leo et al., 2012a, 2012b) where the use of seismic anisotropy as a tool to highlight the fingerprints of background flows in natural subduction zones should be used with additional care. The latter are areas whose subduction evolution, and slab dip and shapes cannot be reconciled in the context of the single slab subduction evolution (e.g., Hayes et al., 2018; Heuret \& Lallemand, 2005; Jarrard, 1986), just because interactions between the locally induced mantle flow and the background mantle flow triggered by neighboring slabs may play a key role (Di Leo et al., 2014; Holt et al., 2017; Király et al., 2016).

Our models also show that in three dimensions, the slab dip does not respond to imposed background flow in the same way to what was expected in 2D (e.g., Ficini et al., 2017; Tao \& O'connell, 1992). Even though the purpose of the paper is not to try to experimentally explain what is tuning the slab dip in nature, our models suggest that the variability of the slab dip in nature cannot be explained a priori only by the background flow. To support this outcome, the experimental slab profiles have been compared to slab profiles of 13 natural subductions, as extracted from the Slab 2.0 database (Hayes et al., 2018). Dip profiles for the natural subduction zones show a larger intra- and inter-dip variability between subduction zones than what was obtained from the models, suggesting that the slab dip can be only slightly affected by a global background flow. Instead, it is tuned by the interplay of a wide range of different ingredients including the lithospheric buoyancy, the upper plate thickness, and the kinematics of the system (e.g., Lallemand et al., 2017) which to some extent may explain why there is no clear correlation between slab dip and subduction vergence for present-day subduction zones (Lallemand et al., 2005) (Figure 13).

\section{Conclusions}

We performed the first series of experiments in which the effect of plate width and background mantle flow on slab geometry in the vertical plane, trench kinematics, and shape, as well as mantle deformation around the slab, are systematically tested in a truly 3D set-up. While we confirm that the width of the subduction zone exerts an important control on the along-trench variability in trench kinematics as well as on trench horizontal shape, we also show that the thickness of the convective mantle is a key ingredient in controlling both the shape of the trench at slab edges and the distance over which the toroidal cells develop, independent of the subduction zone width.

We also show that in subduction zones where both poloidal and toroidal flow are active, the viscous force exerted by the imposed mantle flow only marginally affects the slab geometry in the vertical plane, with differences in slab dip not exceeding $20^{\circ}$ between models within the velocity limits explored here. In particular, we show that for the mantle coming from the foreside of the subduction zone, slab dip is even larger than that for models with mantle coming from the backside, owing to the dominance of the slab pull force over 
Journal of Geophysical Research:Solid Earth

viscous forces associated with mantle flow. Shallow slabs obtained in previous 2D models with background flow may, therefore, not be the general rule and only apply to the center of very large subduction zones, where the toroidal component of the mantle is low, and/or to subduction zones where the slab pull is low (young slabs).

While the effect of background flow is limited on the vertical plane, it plays a fundamental role in the horizontal plane. We show that the curvature of the trench decreases by as much as $50 \%$ for the mantle flow ranging between 0 and $2 \mathrm{~cm} / \mathrm{yr}$, while the trench becomes slightly convex over time for models with background flow coming from the foreside of the subduction zone. The interaction of the subduction-induced mantle flow and background flow disturbs the pattern of horizontal mantle flow, inhibiting the formation of toroidal cells at the slab edges. It could make the careful interpretation of seismic anisotropy a potential tool to identify the activity and strength of background flows in natural subduction zones.

\section{Data Availability Statement}

The original raw pictures for each experiment are published for open access via the GFZ Data Services (Guillaume et al., 2021; https://doi.org/10.5880/fidgeo.2021.012).

\section{Acknowledgments}

The authors thank Armel Menant and Fabio Crameri for their constructives comments. The grant to the Department of Science, Roma Tre University (MIUR-Italy Dipartimenti di Eccellenza, ARTICOLO 1, COMMI 314-337 LEGGE232/2016), is gratefully acknowledged. B. Guillaume was funded by the Topo-4D program of the ESF.

\section{References}

Becker, T. W. (2006). On the effect of temperature and strain-rate dependent viscosity on global mantle flow, net rotation, and plate-driving forces. Geophysical Journal International, 167(2), 943-957. https://doi.org/10.1111/j.1365-246x.2006.03172.x

Becker, T. W. (2017). Superweak asthenosphere in light of upper mantle seismic anisotropy. Geochemistry, Geophysics, Geosystems, 18(5), 1986-2003. https://doi.org/10.1002/2017gc006886

Becker, T. W., \& Faccenna, C. (2009). A review of the role of subduction dynamics for regional and global plate motions. In S. Lallemand, \& F. Funiciello (Eds.), Subduction zone geodynamics (pp. 3-34). https://doi.org/10.1007/978-3-540-87974-9_1

Billen, M. I., Gurnis, M., \& Simons, M. (2003). Multiscale dynamics of the Tonga-Kermadec subduction zone. Geophysical Journal International, 153, 359-388. https://doi.org/10.1046/j.1365-246x.2003.01915.x

Bostrom, R. C. (1971). Westward displacement of the lithosphere. Nature, 234, 536-538. https://doi.org/10.1038/234536a0

Boutelier, D. A., \& Cruden, A. R. (2008). Impact of regional mantle flow on subducting plate geometry and interplate stress: Insights from physical modeling. Geophysical Journal International, 174, 719-732. https://doi.org/10.1111/j.1365-246x.2008.03826.x

Brace, W. F., \& Kohlstedt, D. L. (1980). Limits on lithospheric stress imposed by laboratory experiments. Journal of Geophysical Research, 85(B11), 6248-6252. https://doi.org/10.1029/jb085ib11p06248

Buffett, B. A. (2006). Plate force due to bending at subduction zones. Journal of Geophysical Research, 111, B09405. https://doi. org/10.1029/2006jb004295

Cande, S. C., \& Stegman, D. R. (2011). Indian and African plate motions driven by the push force of the Réunion plume head. Nature, 475, 47-52. https://doi.org/10.1038/nature10174

Capitanio, F. A., Stegman, D. R., Moresi, L. N., \& Sharples, W. (2010). Upper plate controls on deep subduction, trench migrations and deformations at convergent margins. Tectonophysics, 483(1-2), 80-92. https://doi.org/10.1016/j.tecto.2009.08.020

Cardozo, N., \& Allmendinger, R. W. (2009). SSPX: A program to compute strain from displacement/velocity data. Computers \& Geosciences, 35, 1343-1357. https://doi.org/10.1016/j.cageo.2008.05.008

Cerpa, N. G., Guillaume, B., \& Martinod, J. (2018). The interplay between overriding plate kinematics, slab dip and tectonics. Geophysical Journal International, 215, 1789-1802. https://doi.org/10.1093/gji/ggy365

Chertova, M. V., Spakman, W., \& Steinberger, B. (2018). Mantle flow influence on subduction evolution. Earth and Planetary Science Letters, 489, 258-266. https://doi.org/10.1016/j.epsl.2018.02.038

Christensen, U. R. (1996). The influence of trench migration on slab penetration into the lower mantle. Earth and Planetary Science Letters, 140, 27-39. https://doi.org/10.1016/0012-821x(96)00023-4

Cloos, M. (1993). Lithospheric buoyancy and collisional orogenesis: Subduction of oceanic plateaus, continental margins, island arcs, spreading ridges, and seamounts. The Geological Society of America Bulletin, 105, 715-737. https://doi. org/10.1130/0016-7606(1993)105<0715:lbacos >2.3.co;2

Coltice, N., Husson, L., Faccenna, C., \& Arnould, M. (2019). What drives tectonic plates? Science Advances, 5. https://doi.org/10.1126/ sciadv.aax4295

Conrad, C. P., \& Lithgow-Bertelloni, C. (2002). How mantle slabs drive plate tectonics. Science, 298, 207-209. https://doi.org/10.1126/ science. 1074161

Crameri, F., \& Tackley, P. J. (2014). Spontaneous development of arcuate single-sided subduction in global 3-D mantle convection models with a free surface. Journal of Geophysical Research: Solid Earth, 119, 5921-5942. https://doi.org/10.1002/2014jb010939

Crespi, M., Cuffaro, M., Doglioni, C., Giannone, F., \& Riguzzi, F. (2007). Space geodesy validation of the global lithospheric flow. Geophysical Journal International, 168, 491-506. https://doi.org/10.1111/j.1365-246x.2006.03226.x

Cuffaro, M., \& Doglioni, C. (2007). Global kinematics in deep versus shallow hotspot reference frames. In G. R. Foulger, \& D. M. Jurdy (Eds.), Plate, plumes and planetary processes (Vol. 430, pp. 359-374). https://doi.org/10.1130/2007.2430(18)

Davies, G. F. (1995). Penetration of plates and plumes through the mantle transition zone. Earth and Planetary Science Letters, 133, 507516. https://doi.org/10.1016/0012-821x(95)00039-f

Di Leo, J. F., Walker, A. M., Li, Z.-H., Wookey, J., Ribe, N. M., Kendall, J.-M., \& Tommasi, A. (2014). Development of texture and seismic anisotropy during the onset of subduction. Geochemistry, Geophysics, Geosystems, 15(1), 192-212. https://doi.org/10.1002/2013gc005032

Di Leo, J. F., Wookey, J., Hammond, J. O. S., Kendall, J.-M., Kaneshima, S., Inoue, H., et al. (2012a). Mantle flow in regions of complex tectonics: Insights from Indonesia. Geochemistry, Geophysics, Geosystems, 13, Q12008. https://doi.org/10.1029/2012gc004417 
Di Leo, J. F., Wookey, J., Hammond, J. O. S., Kendall, J.-M., Kaneshima, S., Inoue, H., et al. (2012b). Deformation and mantle flow beneath the Sangihe subduction zone from seismic anisotropy. Physics of the Earth and Planetary Interiors, 194-195, 38-54. https://doi. org/10.1016/j.pepi.2012.01.008

Doglioni, C., Carminati, E., Crespi, M., Cuffaro, M., Penati, M., \& Riguzzi, F. (2015). Tectonically asymmetric Earth: From net rotation to polarized westward drift of the lithosphere. Geoscience Frontiers, 6(3), 401-418. https://doi.org/10.1016/j.gsf.2014.02.001

Doglioni, C., Ismail-Zadeh, A., Panza, G., \& Riguzzi, F. (2011). Lithosphere-asthenosphere viscosity contrast and decoupling. Physics of the Earth and Planetary Interiors, 189(1-2), 1-8. https://doi.org/10.1016/j.pepi.2011.09.006

Duarte, J. C., Schellart, W. P., \& Cruden, A. R. (2015). How weak is the subduction zone interface? Geophysical Research Letters, 42(8), 2664-2673. https://doi.org/10.1002/2014gl062876

Faccenda, M., Burlini, L., Gerya, T. V., \& Mainprice, D. (2008). Fault-induced seismic anisotropy by hydration in subducting oceanic plates. Nature, 455, 1097-1100. https://doi.org/10.1038/nature07376

Faccenna, C., Becker, T. W., Lallemand, S., Lagabrielle, Y., Funiciello, F., \& Piromallo, C. (2010). Subduction-triggered magmatic pulses: A new class of plumes? Earth and Planetary Science Letters, 299, 54-68. https://doi.org/10.1016/j.epsl.2010.08.012

Faccenna, C., Funiciello, F., Giardini, D., \& Lucente, P. (2001). Episodic back-arc extension during restricted mantle convection in the Central Mediterranean. Earth and Planetary Science Letters, 187(1-2), 105-116. https://doi.org/10.1016/s0012-821x(01)00280-1

Ficini, E., Dal Zilio, L., Doglioni, C., \& Gerya, T. V. (2017). Horizontal mantle flow controls subduction dynamics. Scientific Reports, 7(7500). https://doi.org/10.1038/s41598-017-06551-y

Forsyth, D., \& Uyeda, S. (1975). On the relative importance of the driving forces of plate motion. Geophysical Journal International, 43, 163-200. https://doi.org/10.1111/j.1365-246x.1975.tb00631.x

Forte, A. M., \& Mitrovica, J. X. (1996). New inferences of mantle viscosity from joint inversion of long-wavelength mantle convection and post-glacial rebound data. Geophysical Research Letters, 23, 1147-1150. https://doi.org/10.1029/96gl00964

Funiciello, F., Faccenna, C., \& Giardini, D. (2004). Role of lateral mantle flow in the evolution of subduction systems: Insights from laboratory experiments. Geophysical Journal International, 157, 1393-1406. https://doi.org/10.1111/j.1365-246x.2004.02313.x

Funiciello, F., Faccenna, C., Giardini, D., \& Regenauer-Lieb, K. (2003). Dynamics of retreating slabs: 2. Insights from three-dimensional laboratory experiments. Journal of Geophysical Research, 108(B4), 2207. https://doi.org/10.1029/2001jb000896

Funiciello, F., Faccenna, C., Heuret, A., Lallemand, S., Di Giuseppe, E., \& Becker, T. W. (2008). Trench migration, net rotation and slab-mantle coupling. Earth and Planetary Science Letters, 271, 233-240. https://doi.org/10.1016/j.epsl.2008.04.006

Funiciello, F., Moroni, M., Piromallo, C., Faccenna, C., Cenedese, A., \& Bui, H. A. (2006). Mapping mantle flow during retreating subduction: Laboratory models analyzed by feature tracking. Journal of Geophysical Research, 111(B03402). https://doi.org/10.1029/2005jb003792

Goes, S., Capitanio, F. A., \& Morra, G. (2008). Evidence of lower-mantle slab penetration phases in plate motions. Nature, 451, 981-984. https://doi.org/10.1038/nature06691

Gripp, A. E., \& Gordon, R. G. (2002). Young tracks of hotspots and current plate velocities. Geophysical Journal International, 150, 321-361. https://doi.org/10.1046/j.1365-246x.2002.01627.x

Guillaume, B., Funiciello, F., \& Faccenna, C. (2021). Experimental data of analogue models of subduction investigating the interplays between mantle flow and slab pullV. 1.0. GFZ Data Services. https://doi.org/10.5880/fidgeo.2021.012

Guillaume, B., Funiciello, F., Faccenna, C., Martinod, J., \& Olivetti, V. (2010). Spreading pulses of the Tyrrhenian Sea during the narrowing of the Calabrian slab. Geology, 38(9), 819-822. https://doi.org/10.1130/g31038.1

Guillaume, B., Hertgen, S., Martinod, J., \& Cerpa, N. G. (2018). Slab dip, surface tectonics: How and when do they change following an acceleration/slow down of the overriding plate? Tectonophysics, 726, 110-120. https://doi.org/10.1016/j.tecto.2018.01.030

Guillaume, B., Moroni, M., Funiciello, F., Martinod, J., \& Faccenna, C. (2010). Mantle flow and dynamic topography associated with slab window opening: Insights from laboratory models. Tectonophysics, 496, 83-98. https://doi.org/10.1016/j.tecto.2010.10.014

Guillou-Frottier, L., Buttles, J., \& Olson, P. (1995). Laboratory experiments on the structure of subducted lithosphere. Earth and Planetary Science Letters, 133, 19-34. https://doi.org/10.1016/0012-821x(95)00045-e

Hager, B. H. (1984). Subducted slabs and the geoid: Constraints on mantle rheology and flow. Journal of Geophysical Research, 89, 60036015. https://doi.org/10.1029/jb089ib07p06003

Hager, B. H., \& O'Connell, R. J. (1979). Kinematic models of large-scale flow in the Earth's mantle. Journal of Geophysical Research, 84, 1031-1048. https://doi.org/10.1029/jb084ib03p01031

Hager, B. H., \& Richards, M. A. (1989). Long-wavelength variations in Earth's geoid: Physical models and dynamical implications. Philosophical Transactions of the Royal Society of London. Series A, Mathematical and Physical Sciences, 328, 309-327.

Hall, C. E., Fischer, K. M., Parmentier, E. M., \& Blackman, D. K. (2000). The influence of plate motions on three-dimensional back arc mantle flow and shear wave splitting. Journal of Geophysical Research, 105(B12), 28009-28033. https://doi.org/10.1029/2000jb900297

Hayes, G. P., Moore, G. L., Portner, D. E., Hearne, M., Flamme, H., Furtney, M., \& Smoczyk, G. M. (2018). Slab2, a comprehensive subduction zone geometry model. Science, 362, 58-61. https://doi.org/10.1126/science.aat4723

Heuret, A., Funiciello, F., Faccenna, C., \& Lallemand, S. (2007). Plate kinematics, slab shape and back-arc stress: A comparison between laboratory models and current subduction zones. Earth and Planetary Science Letters, 256, 473-483. https://doi.org/10.1016/j epsl.2007.02.004

Heuret, A., \& Lallemand, S. (2005). Plate motions, slab dynamics and back-arc deformation. Physics of the Earth and Planetary Interiors, 149, 31-51. https://doi.org/10.1016/j.pepi.2004.08.022

Holt, A. F., Royden, L. H., \& Becker, T. W. (2017). The dynamics of double slab subduction. Geophysical Journal International, 209(1), 250-265.

Hu, J., Faccenda, M., \& Liu, L. (2017). Subduction-controlled mantle flow and seismic anisotropy in South America. Earth and Planetary Science Letters, 470, 13-24. https://doi.org/10.1016/j.epsl.2017.04.027

Husson, L., Guillaume, B., Funiciello, F., Faccenna, C., \& Royden, L. H. (2012). Unraveling topography around subduction zones from laboratory models. Tectonophysics, 526-529, 5-15. https://doi.org/10.1016/j.tecto.2011.09.001

Jadamec, M. A., \& Billen, M. I. (2010). Reconciling surface plate motions with rapid three-dimensional mantle flow around a slab edge. Nature, 465, 338-341. https://doi.org/10.1038/nature09053

Jarrard, R. D. (1986). Relations among subduction parameters. Reviews of Geophysics, 24(2), 217-284. https://doi.org/10.1029/ rg024i002p00217

Kincaid, C., \& Griffiths, R. (2003). Laboratory models of the thermal evolution of the mantle during rollback subduction. Nature, 425, 58-62.

King, S. D. (1998). The influence of rheology, phase changes and equation of state on subduction. Mineralogical Magazine, 62A(2), 783784. https://doi.org/10.1180/minmag.1998.62a.2.80 
King, S. D., \& Hager, B. H. (1990). The relationship between plate velocity and trench viscosity in Newtonian and power-law subduction calculations. Geophysical Research Letters, 17(12), 2409-2412. https://doi.org/10.1029/gl017i013p02409

King, S. D., \& Hager, B. H. (1994). Subducted slabs and the geoid: 1. Numerical experiments with temperature-dependent viscosity. Journal of Geophysical Research, 99, 19843-19852. https://doi.org/10.1029/94jb01552

Király, Á., Capitanio, F. A., Funiciello, F., \& Faccenna, C. (2016). Subduction zone interaction: Controls on arcuate belts. Geology, 44(9), 715-718. https://doi.org/10.1130/g37912.1

Király, Á., Capitanio, F. A., Funiciello, F., \& Faccenna, C. (2017). Subduction induced mantle flow: Length-scales and orientation of the toroidal cell. Earth and Planetary Science Letters, 479, 284-297. https://doi.org/10.1016/j.epsl.2017.09.017

Király, Á., Holt, A. F., Funiciello, F., Faccenna, C., \& Capitanio, F. A. (2018). Modeling slab-slab interactions: Dynamics of outward dipping double-sided subduction systems. Geochemistry, Geophysics, Geosystems, 19, 693-714. https://doi.org/10.1002/2017gc007199

Lallemand, S., Heuret, A., \& Boutelier, D. (2005). On the relationships between slab dip, back-arc stress, upper plate absolute motion, and crustal nature in subduction zones. Geochemistry, Geophysics, Geosystems, 6(9), Q09006. https://doi.org/10.1029/2005gc000917

Lallemand, S., Heuret, A., Li, Z.-H., Di Leo, J. F., \& Ribe, N. M. (2017). Subduction zones parameters, reference module in earth systems and environmental sciences. Elsevier.

Li, Z.-H., Di Leo, J. F., \& Ribe, N. M. (2014). Subduction-induced mantle flow, finite strain, and seismic anisotropy: Numerical modeling. Journal of Geophysical Research: Solid Earth. 119, 5052-5076.

Lithgow-Bertelloni, C., \& Richards, M. A. (1998). The dynamics of Cenozoic and Mesozoic plate motions. Reviews of Geophysics, 36, 27-78. https://doi.org/10.1029/97rg02282

Loiselet, C., Husson, L., \& Braun, J. (2009). From longitudinal slab curvature to slab rheology. Geology, 37, 747-750. https://doi.org/10.1130/ g30052a.1

Long, M. D., \& Silver, P. G. (2008). The subduction zone flow field from seismic anisotropy: A global view. Science, 319(5861), 315-318. https://doi.org/10.1126/science.1150809

Long, M. D., \& Silver, P. G. (2009). Shear wave splitting and mantle anisotropy: Measurements, interpretations, and new directions. Surveys in Geophysics, 30, 407-461. https://doi.org/10.1007/s10712-009-9075-1

Mitrovica, J. X., \& Forte, A. M. (2004). A new inference of mantle viscosity based upon joint inversion of convection and glacial isostatic adjustment data. Earth and Planetary Science Letters, 225, 177-189. https://doi.org/10.1016/j.epsl.2004.06.005

Morra, G., Regenauer-Lieb, K., \& Giardini, D. (2006). Curvature of oceanic arcs. Geology, 34(10), 877-880. https://doi.org/10.1130/g22462.1

Nakajima, J., \& Hasegawa, A. (2004). Shear-wave polarization anisotropy and subduction-induced flow in the mantle wedge of northeastern Japan. Earth and Planetary Science Letters, 225, 365-377. https://doi.org/10.1016/j.epsl.2004.06.011

Obrebski, M., Allen, R. M., Xue, M., \& Hung, S.-H. (2010). Slab-plume interaction beneath the Pacific Northwest. Geophysical Research Letters, 37, L14305. https://doi.org/10.1029/2010gl043489

O'Connell, R. J., Gable, C. W., \& Hager, B. H. (1991). Toroidal-poloidal partitioning of lithospheric plate motions. In R. Sabadini, \& K. Lambeck (Eds.), Glacial isostasy, sea-level and mantle rheology (pp. 535-551).

Piromallo, C., Becker, T. W., Funiciello, F., \& Faccenna, C. (2006). Three-dimensional instantaneous mantle flow induced by subduction. Geophysical Research Letters, 33, L08304. https://doi.org/10.1029/2005gl025390

Ranalli, G. (1995). Rheology of the Earth. Chapman \& Hall.

Ribe, N. M. (2010). Bending mechanics and mode selection in free subduction: A thin-sheet analysis. Geophysical Journal International, 180, 559-576. https://doi.org/10.1111/j.1365-246x.2009.04460.x

Ricard, Y., Doglioni, C., \& Sabadini, R. (1991). Differential rotation between lithosphere and mantle: A consequence of lateral mantle viscosity variations. Journal of Geophysical Research, 96(B5), 8407-8415. https://doi.org/10.1029/91jb00204

Ricard, Y., \& Vigny, C. (1989). Mantle dynamics with induced plate tectonics. Journal of Geophysical Research, 94, 17543-17559. https:// doi.org/10.1029/jb094ib12p17543

Rodríguez-González, J., Negredo, A. M., \& Carminati, E. (2014). Slab-mantle flow interaction: Influence on subduction dynamics and duration. Terra Nova, 26, 265-272. https://doi.org/10.1111/ter.12095

Russo, R. M., \& Silver, P. G. (1994). Trench-parallel flow beneath the Nazca plate from seismic anisotropy. Science, 263(5150), 1105-1111. https://doi.org/10.1126/science.263.5150.1105

Russo, R. M., \& Silver, P. G. (1996). Cordillera formation, mantle dynamics, and the Wilson cycle. Geology, 24(6), 511-514. https://doi.org /10.1130/0091-7613(1996)024<0511:cfmdat>2.3.co;2

Schellart, W. P. (2008). Kinematics and flow patterns in deep mantle and upper mantle subduction models: Influence of the mantle depth and slab to mantle viscosity ratio. Geochemistry, Geophysics, Geosystems, 9, Q03014. https://doi.org/10.1029/2007gc001656

Schellart, W. P. (2010). Evolution of subduction zone curvature and its dependence on the trench velocity and the slab to upper mantle viscosity ratio. Journal of Geophysical Research, 115, B11406. https://doi.org/10.1029/2009jb006643

Schellart, W. P., Freeman, J., Stegman, D. R., Moresi, L., \& May, D. (2007). Evolution and diversity of subduction zones controlled by slab width. Nature, 446, 308-311. https://doi.org/10.1038/nature05615

Shephard, G. E., Matthews, K. J., Hosseini, K., \& Domeier, M. (2017). On the consistency of seismically imaged lower mantle slabs. Scientific Reports, 7, 10976. https://doi.org/10.1038/s41598-017-11039-w

Sobolev, S. V., \& Brown, M. (2019). Surface erosion events controlled the evolution of plate tectonics on Earth. Nature, 570, 52-57. https:// doi.org/10.1038/s41586-019-1258-4

Stegman, D. R., Farrington, R., Capitanio, F. A., \& Schellart, W. P. (2010). A regime diagram for subduction styles from 3-D numerical models of free subduction. Tectonophysics, 483, 29-45. https://doi.org/10.1016/j.tecto.2009.08.041

Stegman, D. R., Freeman, J., Schellart, W. P., Moresi, L., \& May, D. (2006). Influence of trench width on subduction hinge retreat rates in 3-D models of slab rollback. Geochemistry, Geophysics, Geosystems, 7(3), Q03012. https://doi.org/10.1029/2005gc001056

Sternai, P., Jolivet, L., Menant, A., \& Gerya, T. (2014). Driving the upper plate surface deformation by slab rollback and mantle flow. Earth and Planetary Science Letters, 405, 110-118. https://doi.org/10.1016/j.epsl.2014.08.023

Strak, V., \& Schellart, W. P. (2016). Control of slab width on subduction-induced upper mantle flow and associated upwellings: Insights from analog models. Journal of Geophysical Research: Solid Earth, 121, 4641-4654. https://doi.org/10.1002/2015jb012545

Tao, W. C., \& O'connell, R. J. (1992). Ablative subduction: A two-sided alternative to the conventional subduction model. Journal of Geophysical Research, 97(B6), 8877-8904. https://doi.org/10.1029/91jb02422

Thielicke, W. (2014). The flapping flight of birds-Analysis and application (Ph.D. thesis).

Thielicke, W., \& Stamhuis, E. J. (2014). PIVlab-Towards user-friendly, affordable and accurate digital particle image velocimetry in MATLAB. Journal of Open Research Software, 2(1).

Turcotte, D., \& Schubert, G. (1982). Geodynamics: Applications of continuum physics to geological problems. John Wiley and Sons. 
Uyeda, S., \& Kanamori, H. (1979). Back-arc opening and the mode of subduction. Journal of Geophysical Research, 84(B3), 1049-1061. https://doi.org/10.1029/jb084ib03p01049

Van Hunen, J., van den Berg, A. P., \& Vlaar, N. J. (2000). A thermo-mechanical model of horizontal subduction below an overriding plate. Earth and Planetary Science Letters, 182(2), 157-169. https://doi.org/10.1016/s0012-821x(00)00240-5

Wu, B., Conrad, C. P., Heuret, A., Lithgow-Bertelloni, C., \& Lallemand, S. (2008). Reconciling strong slab pull and weak plate bending: The plate motion constraint on the strength of mantle slabs. Earth and Planetary Science Letters, 272, 412-421. https://doi.org/10.1016/j. epsl.2008.05.009

Zhong, S., \& Gurnis, M. (1994). Controls on trench topography from dynamic models of subducted slabs. Journal of Geophysical Research, 99(B8), 15683-15695. https://doi.org/10.1029/94jb00809 